\title{
PREDATOR DIVERSITY IMPACTS HERBIVORE ABUNDANCE AND BEHAVIOR WITH CASCADING EFFECTS ON THE PREVALENCE OF A VECTOR-BORNE PLANT PATHOGEN
}

A Dissertation
Presented to
The Faculty of the Graduate School
At the University of Missouri
In Partial Fulfillment
Of the Requirements for the Degree
Doctor of Philosophy
BLIZABETH YIM LONG
Beborah L. Finke, Dissertation Supervisor

MAY 2013 
(C) Copyright by Elizabeth Yim Long 2013

All Rights Reserved 
The undersigned, appointed by the dean of the Graduate School, have examined the Dissertation entitled

PREDATOR DIVERSITY IMPACTS HERBIVORE ABUNDANCE AND BEHAVIOR WITH CASCADING EFFECTS ON THE PREVALENCE OF A VECTOR-BORNE PLANT PATHOGEN

Presented by Elizabeth Yim Long

A candidate for the degree of

Doctor of Philosophy

And hereby certify that, in their opinion, it is worthy of acceptance.

Dr. Deborah L. Finke, Division of Plant Sciences

Dr. Candace Galen, Division of Biological Sciences

Dr. Richard Houseman, Division of Plant Sciences

Dr. James Schoelz, Division of Plant Sciences 


\section{ACKNOWLEDGEMENTS}

I would like to express my most sincere appreciation to my $\mathrm{PhD}$ advisor, Deborah Finke, for encouraging me without ceasing, for challenging me to think critically, and for providing me with a truly fantastic example of how to be a devoted colleague and mentor. I also thank Debbie for her commitment to my personal development, not only as a scientist, but also as a teacher and a professional in the fields of Ecology and Entomology. I am very thankful to my committee members, Drs. Candace Galen, Richard Houseman, and James Schoelz for their support and encouragement during my time as a graduate student. I would also like to thank Dr. Schoelz for opening his laboratory to me and training me personally in the use of molecular techniques.

I also thank several individuals who have provided long-distance support to me: I thank Dr. Joseph Anderson at Purdue University for providing me with each of the components of my plant-insect-pathogen system on more than one occasion. I thank Dr. Charles Mitchell at the University of North Carolina Chapel Hill for allowing me to visit his lab facilities and for sharing his aphid-virus inoculation protocols with me. I thank Dr. Carlos Angel, a previous student in Dr. James Schoelz's lab, for sharing his time and incredible knowledge of the molecular techniques required to conduct RNA extractions and PCR amplifications; without his training and support, I would not have been able to conduct any of the molecular tests required to determine if plants were virus-positive or virus-negative. I thank Michelle Brooks and Tim Reinbott for their fantastic and unending support in making sure that all things were prepared and in place for greenhouse and field experiments. I also thank Debbie Allen and Dr. Mark Hannink for 
their enthusiastic support, and for inviting me to be involved in recruitment and outreach activities that have shaped my professional development in many positive ways. I also thank June Hancock and David Hill at Syngenta Seeds, for generously supplying me with wheat for the purposes of my research.

Within the University of Missouri, I would like to thank the Life Sciences Fellowship Program and the Division of Plant Sciences Program for providing me with financial support during my time as a graduate student. I also want to express sincere thanks to all the graduate and undergraduate members of the Finke lab past and present, especially Lauren, Camila, Andrew, and Jeb, who supported me and worked side-by-side with me in the field and greenhouse, often during blistering hot or muddy conditions. I also thank the wonderful faculty and the graduate students in the Entomology Program Area for their support and for the sense of community they provided during my time as a graduate student.

Last but by no means least, I express my warmest and most loving thanks to my Dad, stepmom, sister, brother-in-law, grandfather and my late-grandmother, all of whom have supported me, prayed for me, and encouraged me without ceasing to pursue my interest in science, even when my interests have called me far from home. My achievements are a testimony of your love and faith in me, and I am very blessed have you as my family. 


\section{TABLE OF CONTENTS}

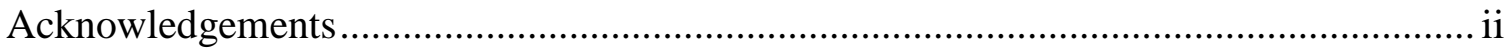

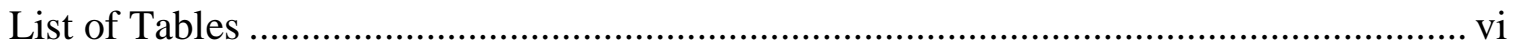

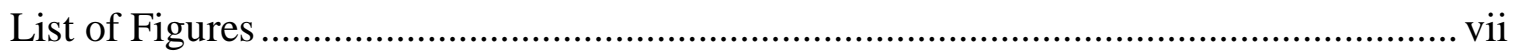

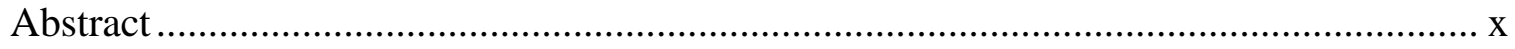

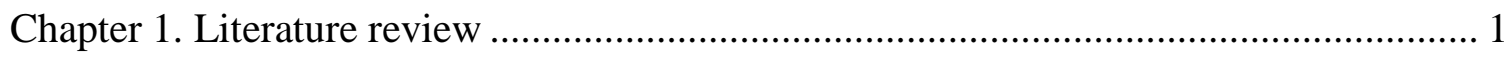

Chapter 2. Predator diversity enhances herbivore suppression and decreases spatial

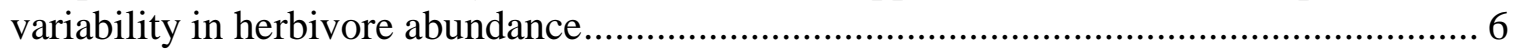

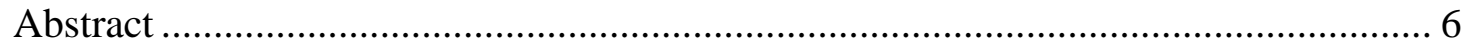

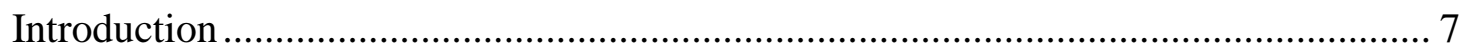

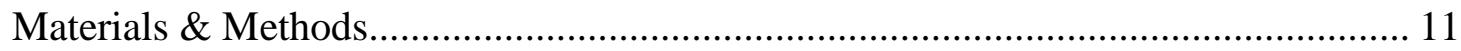

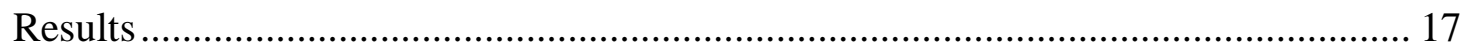

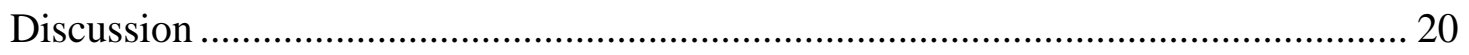

Chapter 3. The contribution of predator identity to the suppression of herbivores by a

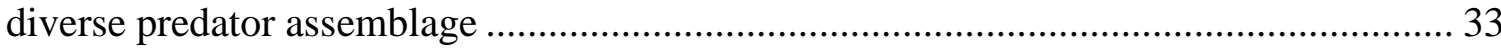

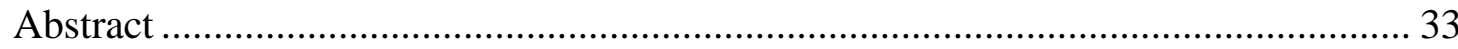

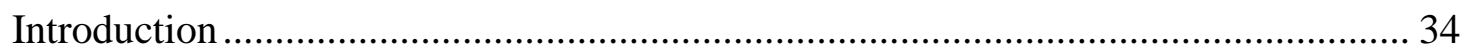

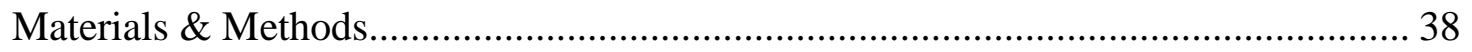

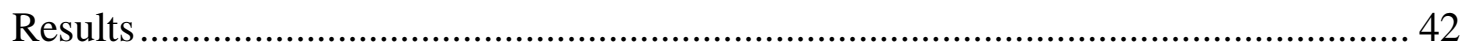

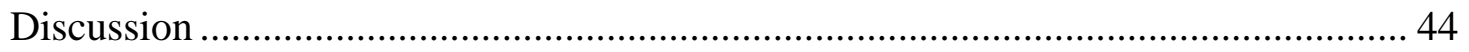

Chapter 4. Cascading effects of predators on a vector-borne plant pathogen are not altered

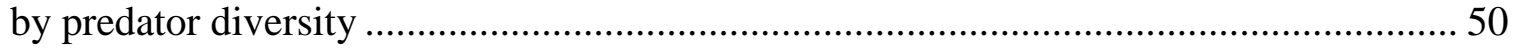

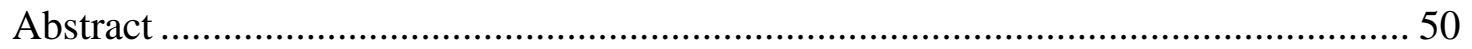

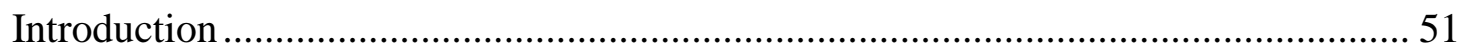

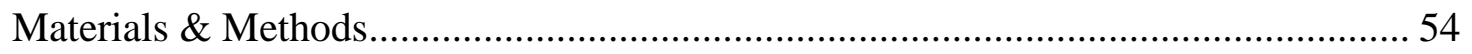




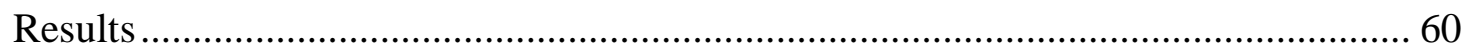

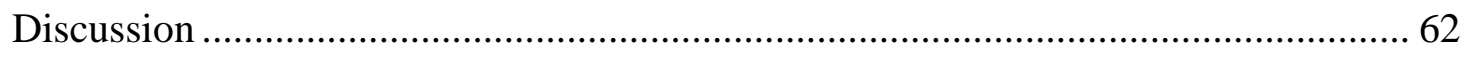

Chapter 5. The impact of acquisition access period on the efficiency of Cereal Yellow Dwarf Virus transmission by the aphid vector Rhopalosiphum padi (Hemiptera:

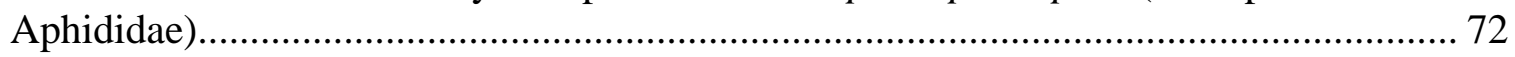

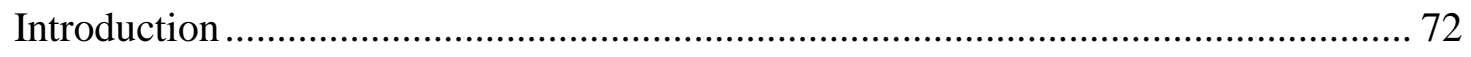

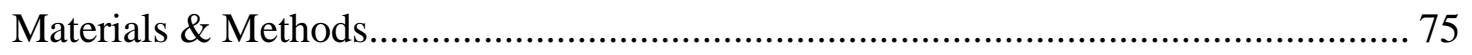

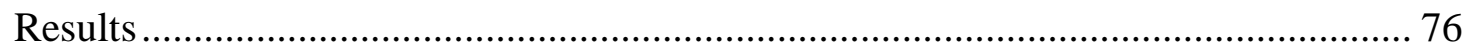

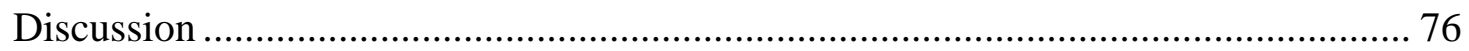

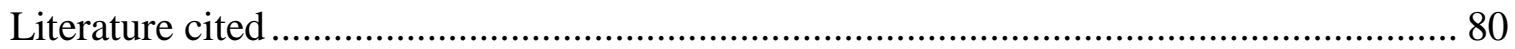

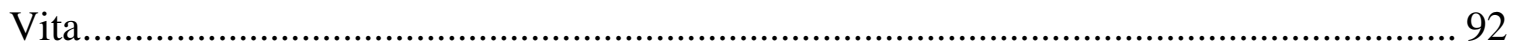




\section{LIST OF TABLES}

$\begin{array}{ll}\text { Table Page } & \end{array}$

1. Detection probability of bird cherry-oat aphids (Rhopalosiphum padi) on wheat plants at set time intervals after aphid release... 


\section{LIST OF FIGURES}

Figure

Page

1. Arrangement of the wheat habitat in each greenhouse mesocosm. Each tray consisted of 72 wheat plants in a 12 x 6 design. For the purposes of evaluating aphid distribution, the habitat was further divided into 4 equal sections (numbered 1-4), with segment 1 being the closest and 4 the most distal from the site of initial aphid release.

2. Natural enemy species combinations used to create treatment replicates in greenhouse mesocosms. An " $x$ " denotes the presence of a predator species in that particular treatment replicate.

3. Arrangement of the wheat habitat in each field cage. Each wheat plot consisted of approximately 450 plants. For the purposes of evaluating aphid distribution, the habitat was divided into 4 equal sections (numbered 1-4), with segment 1 being the closest and 4 the most distal from the site of initial aphid release.

4. Natural enemy species combinations used to create treatment replicates in field cages. An " $x$ " denotes the presence of a predator species in that particular treatment replicate.

5. Natural enemy species combinations used to create treatment replicates in laboratory terraria. An " $x$ " denotes the presence of a predator species in that particular treatment replicate.

6. The effect of increasing predator species richness on bird cherry-oat aphid (Rhopalosiphum padi) abundance in (A) greenhouse mesocosms after 48 hours, and (B) field cages after 4 weeks. LSmeans \pm 1 SEM with different letters are significantly different at the $p<0.05$ level.

7. The effect of increasing predator species richness on the spatial stability (variance to mean ratio) of bird cherry-oat aphid (Rhopalosiphum padi) abundance across habitat quadrants in (A) greenhouse mesocosms after 48 hours, and (B) field cages after 4 weeks. LSmeans \pm 1 SEM with different letters are significantly different at the $p<0.05$ level.

8. The effect of predator species richness on (A) the average number of predators (out of 4) observed per plant and (B) the spatial stability 
(variance to mean ratio) in the abundance of predators across 5 wheat plants, during a 48-hr observational study. LSmeans \pm 1 SEM with different letters are significantly different at the $p<0.05$ level.

9. The effect of predator diversity (no-predator control, 1 predator species present or 4 predator species present) and predator species composition on the total number of bird cherry-oat aphids (Rhopalosiphum padi) remaining in field cages after 4 weeks. The five unique species compositions comprising the 1-species treatment are compared to the average of the 4-species treatments, and the five unique species compositions comprising the 4-species treatment are compared to the average of the 1 -species treatments. LSmeans \pm 1 SEM are shown.

10. The impact of increasing Coleomegilla maculata beetle density on bird cherry-oat aphid (Rhopalosiphum padi) abundance in wheat habitats at (A) low aphid density and (B) high aphid density. LSmeans \pm 1 SEM with different letters are significantly different at the $p<0.05$ level. Note that $\mathrm{Y}$-axis in panel $\mathrm{B}$ begins at 1.0

11. Arrangement of wheat habitat with each box representing a single wheat plant. Two-hundred viruliferous bird cherry-oat aphids (Rhopalosiphum padi) were haphazardly released onto the two most distal rows of plants (denoted by dots). Pathogen prevalence was calculated as the proportion of 16 sub-sampled wheat plants (gray boxes with an "X") that tested positive for CYDV-RPV....

12. Arrangement of 5 wheat plants in 10-gallon terraria to conduct visual observations of bird cherry-oat aphid (Rhopalosiphum padi) movement in response to predators

13. The effect of predator species richness (no predators, 1 species or 4 species present) on (A) pathogen prevalence (the proportion of wheat plants infected with CYDV-RPV out of a sub-sample of 16 plants), (B) the abundance of bird cherry-oat aphids (Rhopalosiphum padi), vectors of CYDV-RPV, and (C) the proportion of wheat plants (out of 60 ) occupied by at least one $R$. padi aphid after a 48-hr interaction period in greenhouse mesocosms. LSmeans \pm 1 SEM with different letters are significantly different at the $p<0.05$ level.

14. The relationship between vector (bird cherry-oat aphid Rhopalosiphum padi) abundance and pathogen prevalence (the proportion of wheat plants infected with CYDV-RPV) with predator diversity treatment used as a covariate: $\bullet=$ no-predator control, $\circ=1$ predator species 
present, and $\boldsymbol{\nabla}=4$ predator species present. There was no relationship between vector abundance and pathogen prevalence $\left(Y=6 \mathrm{e}^{-4} x+\right.$ $0.1494, r^{2}=0.03, p=0.78$ )

15. The effect of predator species richness (no predators, 1 species or 3 species present) on the average number of plants moved by bird cherry-oat aphids (Rhopalosiphum padi) per 6-hr observational period. Nine visual observations were made over a 48 -hr period. LSmeans \pm 1 SEM with different letters are significantly different at the $p<0.05$ level.

16. The impact of vector acquisition feeding time (acquisition access period) on the transmission efficiency (proportion of plants infected) of CYDV-RPV by bird cherry-oat aphids (Rhopalosiphum padi) in soft red winter wheat. LSmeans \pm 1 SEM are shown. 


\begin{abstract}
There is growing concern about the loss of biodiversity; particularly of organisms at higher trophic levels, such as predators, which face a disproportionately higher risk of extinction. As predator diversity declines there may be consequences for critical ecosystem processes such as disease dynamics, and/or valuable ecosystem services like natural pest suppression. In this study, I examine the impact of declining predator diversity on 1) the strength and spatial stability of suppression of a generalist sap-feeding insect, the bird cherry-oat aphid Rhopalosiphum padi, residing in wheat (Triticum aestivum) habitats, and 2) the mechanism contributing to any observed predator diversity effects on aphid suppression. Furthermore, I evaluate 3) any cascading impacts of predator diversity loss on the prevalence of a plant pathogen, cereal yellow dwarf virus, which is vectored from plant to plant exclusively by aphids. By manipulating predator species richness and identity in experimental mesocosms in the laboratory, greenhouse and field settings, I found that predator diversity enhanced both the overall strength and spatial stability of herbivore suppression across the habitat. The greater suppression of aphid populations by diverse predator communities was attributed, at least in part, to a species identity effect whereby more diverse predator assemblages were statistically more likely to contain the predator species exhibiting the highest rate of aphid consumption. Predator diversity did not alter the prevalence of the aphid-vectored plant pathogen; however, the presence of predators significantly reduced pathogen prevalence by stimulating the movement and altering the feeding behavior of pathogen vectors. These results suggest that conserving predator diversity in natural and managed ecosystems may
\end{abstract}


enhance the magnitude and spatial consistency of herbivore suppression, and potentially diminish the prevalence of some vector-borne plant pathogens; however, the contributions of particular predator species may be greater than the impact of predator diversity overall. 


\section{CHAPTER 1.}

\section{LITERATURE REVIEW}

Despite the currently rapid rate of species extinctions, little is known about the consequences of biodiversity loss for the dynamics of diseases (Keesing et al. 2006). Of particular importance to the dynamics of vector-borne diseases may be the loss of organisms in higher trophic levels, such as predators, which are predicted to be at greater risk of extinction than other organisms occurring lower in the food chain (Dobson et al. 2006). The loss of plant diversity and consequences for primary production have received great attention, however fewer studies have focused on the consequences of diminishing predator diversity (Cardinale et al. 2006). Aside from the loss of valuable ecosystem services, declining predator diversity may have implications for the spread of plant diseases via impacts on herbivores that act as pathogen vectors. Many studies have addressed the key roles predators play in ecosystems; predators have been shown to exert cascading impacts within food webs (Schmitz 1998, Schmitz et al. 2000, Finke and Denno 2004, Byrnes et al. 2005, Finke and Denno 2005) and strengthen herbivore suppression (Losey and Denno 1998b, Snyder et al. 2005, Snyder et al. 2006, Straub and Snyder 2006, Finke and Snyder 2008), but the role of predator diversity in the context of disease ecology/risk is an area warranting further investigation (Lafferty 2004, Keesing et al. 2006, Holt and Roy 2007). Insect-vectored pathogens can exert strong negative impacts on plant species harvested for human consumption, resulting not only in significant reductions in yield loss (Plumb and Thresh 1983, Pike 1990, Banks et al. 
1995, Perry et al. 2000) but also the potentially increased costs of management and environmental damage resulting from pesticide use. In light of the importance of agriculture for feeding and fueling a growing population, it is increasingly important to gain an understanding of the role that predator diversity plays in vector-borne disease dynamics.

One vector-borne plant pathogen system, the aphid-vectored barley and cereal yellow dwarf viruses (B/CYDVs), provides a great starting point for investigating the impacts of predator diversity on pathogen prevalence because the host-vector-pathogen relationships in this system have been well-studied for more than 40 years (D'Arcy and Burnett 1995). Belonging to the families Luteoviridae and Poleroviridae respectively, the B/CYDVs are a globally important group of cereal crop pathogens that are endemic to all the major wheat growing areas of the United States (Burnett and Plumb 1998, Perry et al. 2000). These viruses are reported to be transmitted by at least 25 species of aphids in an obligate and persistent manner (D'Arcy and Burnett 1995). Therefore, these viruses are dependent on an aphid for transmission from plant to plant. Aphids become B/CYDV vectors (viruliferous) by ingesting the phloem sap of infected host plants. Furthermore, these persistently-transmitted pathogens are intimately associated with the vector such that pathogen particles are actively acquired by the aphid hindgut and then re-circulated to the accessory salivary glands, where they become available to be inoculated into a host (Irwin and Thresh 1990, Gray and Gildow 2003). This process of pathogen acquisition often requires relatively longer periods of feeding by the vector (Power and Gray 1995), and is followed by a latent period during which the vector cannot inoculate the pathogen into a host. However, once acquisition has occurred successfully, these pathogens are 
often capable of being inoculated into plant hosts for the remainder of the vector's life cycle (Nault 1997, Gray and Banerjee 1999), thus contributing to the persistent nature of pathogen transmission. Barley and cereal yellow dwarf viruses are not transmitted vertically in aphids; therefore the progeny of infected adults are born virus-free, and the virus does not replicate within the vector (Nault 1997, Gray and Gildow 2003).

Aphid species in the U. S. that are most important for transmitting these viruses are the bird cherry-oat aphid Rhopalosiphum padi (Linnaeus) (Hemiptera:Aphididae), the english grain aphid Sitobion avenae (Fabricius) (Hemiptera:Aphididae) and the greenbug aphid Schizaphis graminum (Rondani) (Hemiptera:Aphididae), and these species are commonly found on small grains (D'Arcy and Burnett 1995). Furthermore, there are multiple strains of B/CYDVs with varying levels of virulence (depending on crop species infected), and vectors differ widely in the efficiency with which they transmit each strain (Rochow 1970, Miller and and Rasochová 1997). Variations in virus-vector transmission efficiencies are thought to be the result of species-specific interactions in the recognition and binding of virus particles (virions) to key receptors in the aphid gut (Gray and Gildow 2003). The barley yellow dwarf Luteoviruses are comprised of four viral strains: BYDV-PAV, -MAV, -SGV, and -RMV, while cereal yellow dwarf virus consists of a single strain of Polerovirus: CYDV-RPV. Infection by this suite of viruses can have serious economic consequences, as infection can give rise to symptoms such as stunting, reduced root growth, reduced tillering, yellowing of foliage, and even death, although infections in wheat can be asymptomatic and still reduce crop yields (Irwin and Thresh 1990, Perry et al. 2000). Strategies for managing outbreaks of this disease in cereals and other small grains have included suppressing vector populations via biological control 
efforts and habitat manipulation (Brewer and Elliott 2004); however, disease management is most often achieved via the use of plant lines that are tolerant or resistant to various B/CYDV isolates (Miller and and Rasochová 1997).

The spread of B/CYDVs is strongly determined by aphid density (Power and Gray 1995), therefore, factors such as predation which influence aphid abundance are likely to impact the prevalence of these pathogens. Herbivore-natural enemy interactions in wheat are not well understood, and the lack of knowledge of the importance of insect predators in wheat systems makes predicting pest, and therefore disease outbreaks difficult (Schmidt et al. 2003). Common generalist predators in wheat include insects from the families Nabidae (Hemiptera), Chrysopidae (Neuroptera), Coccinellidae (Coleoptera), and Lygaeidae (Hemiptera) and all have the potential to suppress cereal aphid populations in grain crops (Kring et al. 1985, Rice and Wilde 1988, Schmidt et al. 2004). As we expand our knowledge of the role of insect predators in the community dynamics of cereal crops, we can begin to shed light on the nature of predator-vectordisease dynamics in these systems.

Predators can impact aphid vectors and therefore disease risk in two ways: via consumptive effects, in which predators impact vector densities directly via consumption, or via non-consumptive effects, in which the presence of predators results in altered vector behavior (Preisser et al. 2005, Nelson 2007). The ability of predators to decrease the overall abundance of vectors through consumption may be impacted by species richness in the predator community such that higher predator diversity may have positive, negative, or no effects on the suppression of vector populations. For example, a diverse predator assemblage may be beneficial and reduce disease risk if multiple predators act 
synergistically to reduce vector densities (Wilby et al. 2005, Snyder et al. 2006, Finke and Snyder 2008). Conversely, if multiple predators interfere with each other or act antagonistically (Finke and Denno 2004, Bruno and O'Connor 2005, Cardinale et al. 2006), a diverse predator assemblage may allow vector populations to escape predator control, potentially resulting in amplified disease risk.

In addition to impacting vector densities via acts of predation, predators can also impact pathogen vectors in a non-consumptive fashion by altering the feeding or dispersal behaviors of vectors. Greater diversity in the predator community may reduce disease risk if vectors spend more time avoiding detection by multiple predator species than they do feeding (Nelson 2007), thereby reducing the likelihood of pathogen transmission. However, in a case where vectors are more likely to disperse as a result of perceived predator threat (Tamaki et al. 1970), a diverse assemblage of predators may increase pathogen prevalence locally and perhaps even regionally by stimulating vectors to disperse greater distances as a result of intensified predator cues.

Although effects may vary depending on vector species and study system, it seems plausible that declines in predator diversity could dampen or amplify disease outbreaks within a host population via cascading consumptive or non-consumptive effects on vector prey. The purpose of this research was to document the impact of altering predator diversity on 1) the suppression of CYDV vectors, 2) the prevalence of the CYDV pathogen in wheat and (3) to determine the mechanism behind any observed impacts of predator diversity on the prevalence of CYDV in wheat. 


\title{
CHAPTER 2.
}

\section{PREDATOR DIVERSITY ENHANCES HERBIVORE SUPPRESSION AND DECREASES SPATIAL VARIABILITY IN HERBIVORE ABUNDANCE}

\begin{abstract}
Diversity has been shown to mediate the outcome of several ecological processes; however fewer studies have investigated the influence of diversity on the stability of these processes. In this chapter, I evaluate the impact of predator species richness on the ecosystem service of herbivore suppression. Specifically, I evaluate how the overall strength and spatial stability of bird cherry-oat aphid (Rhopalosiphum padi) suppression across a soft red winter wheat (Triticum aestivum) habitat is impacted by altered predator species richness. By manipulating diversity within a guild of commonly occurring predatory insects I show that there are benefits of enhanced predator diversity to both the overall efficacy and spatial stability of aphid suppression. I found that predator suppression of these sap-feeding herbivores was strongest in the presence of species-rich predator assemblages as compared to singlespecies predator assemblages, and furthermore this benefit of predator diversity manifested itself such that the variation in the spatial abundance of aphid prey was less in the presence of diverse predator communities. As a result, herbivore suppression was stronger and more reliable/stable across the habitat when predator communities included multiple rather than only a single predator species. Consistent with this result, I also found that the number of individual predators on plants increased and the variance in the spatial abundance of predators decreased with greater predator diversity. These results
\end{abstract}


suggest that conserving predator biodiversity in natural and managed systems can be beneficial for both the strength and spatial stability of herbivore suppression as increasing predator diversity enhances the similarity of predator communities across the landscape.

\section{INTRODUCTION}

Human-mediated changes to the environment pose a threat to species worldwide, raising concern over the sustainability of ecosystem functions and services (Vitousek et al. 1997, Loreau et al. 2001, Cardinale et al. 2012). Most studies investigate the magnitude of the impact of biodiversity loss on overall ecosystem performance and find that, in general, declining diversity negatively impacts ecosystem performance (Balvanera et al. 2006, Cardinale et al. 2006, Worm et al. 2006). However, diversity loss is also predicted to threaten the stability of ecosystem properties (McGrady-Steed et al. 1997, Naeem and Li 1997, McCann et al. 1998, Tilman et al. 2006, Haddad et al. 2011). Stability is typically described as a reduction in the variability of ecosystem performance over time or a decrease in the susceptibility of ecosystems to external perturbations such as invading species (Cottingham et al. 2001, Balvanera et al. 2006, Worm et al. 2006). What is often overlooked is the potential for biodiversity to provide spatial stability, or more consistent ecosystem performance across space. It has been hypothesized that the predictability of ecosystem functioning across space will increase with diversity, because increasing diversity will enhance the similarity of species compositions across the habitat (Fukami et al. 2001). However, few studies have explicitly tested this hypothesis, and with mixed results (France and Duffy 2006, Weigelt et al. 2008). 
The majority of studies investigating the consequences of diversity loss for ecosystem performance and stability have focused on primary producers and their consumers, despite the fact that higher trophic level organisms, like predators, are predicted to be at greater risk of extinction (Pauly et al. 1998, Petchey et al. 1999, Dobson et al. 2006). The loss of predator diversity is of particular concern because of the valuable ecosystem services provided by predators, such as natural pest suppression (Cardinale et al. 2003, Duffy 2003, Ives et al. 2005, Losey and Vaughan 2006, Bruno and Cardinale 2008, Straub et al. 2008, Finke and Snyder 2010). The studies that do incorporate predator diversity commonly focus on the consequences of diversity loss for the overall sign and strength of herbivore suppression (Schmitz 2007, Bruno and Cardinale 2008, Finke and Snyder 2010, Tylianakis and Romo 2010). Most often, enhancing predator diversity positively impacts herbivore suppression, with cascading benefits for plant biomass (Bruno and O'Connor 2005, Byrnes et al. 2005, Snyder et al. 2006, Otto et al. 2008, Reynolds and Bruno 2013). But in some cases, increasing predator diversity decreases herbivore suppression, particularly in systems where antagonistic interactions between predator species, like intraguild predation, dominate (Denno et al. 2004, Finke and Denno 2005, Jonsson et al. 2007). Overall, responses vary widely and many conclude that the consequences of altered predator species richness for herbivore suppression are context-dependent (Schmitz 2007, Letourneau et al. 2009, Finke and Snyder 2010, Tylianakis and Romo 2010).

While we are developing an understanding of the impact of predator diversity loss on the overall strength of herbivore suppression, we know much less about the consequences of predator diversity for the stability of herbivore suppression across time 
and space. Predators, in general, are predicted to enhance temporal stability by increasing food web complexity and linking the dynamics of sub-webs within the larger community (McCann et al. 1998, Thébault and Loreau 2005, Rooney et al. 2006, Tscharntke et al. 2007, Jiang and Pu 2009). And increasing predator diversity has been implicated in conferring greater temporal stability by damping the strength of trophic cascades (Finke and Denno 2004). Whether greater predator diversity also contributes to spatial stability requires further investigation.

Predators and their prey are often mobile organisms; therefore, spatial processes may play a particularly important role in determining the impact of predator diversity loss on herbivore populations (Schmitz 2007). Spatial variation in the strength of herbivore suppression could arise if, for example, prey emigrate from local habitats in response to the presence of predators (Cronin et al. 2004), or if predators aggregate and consume patchily-distributed prey in a positively or negatively density-dependent manner (Cardinale et al. 2006). Either case may result in a re-distribution of prey throughout the regional habitat. Predator diversity may further influence spatial variation in herbivore populations via these same mechanisms. For example, the presence of multiple predator species may provide a stronger cue of predator presence, stimulating greater herbivore emigration (Steffan and Snyder 2010), or a combination of predator species may result in more consistent suppression across prey patches if some predator species function best at low prey density and some function best at high prey density (Straub et al. 2008, Tylianakis and Romo 2010). By providing 'spatial insurance', processes like dispersal are predicted to contribute to the temporal stability of ecosystem functioning (Loreau et al. 2003), but may also result in spatial instability (Howeth and Leibold 2010). Yet, the 
majority of studies investigating predator diversity effects on herbivore suppression assess the impact of predator treatments on the magnitude of total herbivore population suppression, without considering the potential for spatial variability in treatment effects across the habitat.

Using the diverse community of arthropods inhabiting wheat (Triticum aestivum L.) agroecosystems, I tested the hypothesis that increasing predator diversity enhances the strength and spatial stability of prey suppression, a valuable ecosystem service provided by predators. I focused on one species of herbivorous insect, the bird cherry-oat aphid, Rhopalosiphum padi (Linnaeus) (Hemiptera: Aphididae), a phloem-feeding generalist of cereal grains. These aphids are attacked by a diverse guild of natural enemies that have the potential to suppress cereal aphid populations in grain crops (Kring et al. 1985, Rice and Wilde 1988, Schmidt et al. 2004), including insects from the families Anthocoridae (Hemiptera), Lygaeidae (Hemiptera), Nabidae (Hemiptera), Chrysopidae (Neuroptera), Coccinellidae (Coleoptera), and Braconidae (Hymenoptera). In the greenhouse and the field, I conducted manipulations of predator species richness (i.e. the number of predator species present) and found that increasing species richness enhances the overall suppression of $R$. padi aphid populations and decreases the spatial variation in $R$. padi aphid abundance across the habitat. This work suggests that the loss of predator diversity may threaten the strength and spatial reliability of herbivore suppression in natural and managed landscapes. 


\section{MATERIALS \& METHODS}

Impact of predator diversity on the strength and spatial stability of aphid suppression in greenhouse mesocosms

I evaluated the impact of predator species richness on the total abundance and spatial variation of $R$. padi aphid populations in wheat mesocosms at the University of Missouri Ashland Road greenhouse facility. The experimental units were $60 \mathrm{~cm} \mathrm{x} 60 \mathrm{~cm} \mathrm{x}$ $60 \mathrm{~cm}$ bug dorm insect cages (MegaView Science Co., Ltd., Taichung, Taiwan) containing a single tray of 10-day old wheat plants arranged in a 12 x 6 grid design for a total of 72 plants per habitat. The wheat habitat was further sub-divided into four equal quadrants, each containing 3 rows of 6 plants (18 plants total) (Fig. 1). A total of $200 R$. padi aphids were released into one quadrant of the wheat habitat in each cage, and the aphids were allowed uninhibited access to colonize the other three quadrants. The aphids were given 24-hours to settle on plants and become established before the addition of predators.

I created the predator treatments using the following predator species: the pinkspotted lady beetle Coleomegilla maculata (DeGeer) (Coleoptera: Coccinellidae), the seven-spotted lady beetle Coccinella septempunctata (Linnaeus) (Coleoptera: Coccinellidae), the parasitoid wasp Aphidius colemani (Viereck) (Hymenoptera: Braconidae), the damsel bug Nabis americoferus (Carayon) (Hemiptera: Nabidae), and the green lacewing, Chrysoperla carnea (Stephens) (Neuroptera: Chrysopidae). I used these 5 predator species because they occurred commonly and were abundant based on visual counts made in wheat fields. Larvae of the green lacewing and adult parasitoid wasps were obtained from Rincon-Vitova Insectaries (Ventura, CA), while other adult 
predator species were collected in the field by hand or using a D-vac suction sampler (Rincon-Vitova Insectaries, Ventura, CA). Predator assemblages were created from the pool of five predator species according to three predator diversity treatments: (1) Nopredator control, (2) 1 predator species present or (3) 4 predator species present. The 1species predator treatment and 4-species predator treatment each included 15 replicates (three replicates of each of the five unique species compositions possible from the pool of 5 predator taxa) and the No-predator control treatment included 6 replicates, for a total of 36 experimental units (Fig. 2). I utilized a substitutive design wherein total predator density across treatments containing predators was held constant at 4 individuals per cage; thus, the 1-species treatment contained 4 individuals of the same predator species while the 4 -species treatment contained 1 individual of each of 4 predator species.

After the 24-hour aphid settling period, predators were released into cages and allowed 48 hours to exert impacts on R. padi aphid populations. After this time, each cage was hand-searched to collect predators, and all remaining aphids in the four quadrants were visually counted. Although $R$. padi aphids are small, my ability to detect and count aphids on wheat plants was consistently high based on the detection frequency of known numbers of aphids released on wheat plants at $15 \mathrm{~min}, 30 \mathrm{~min}, 1 \mathrm{hr}$, and $6 \mathrm{hrs}$ after release (Table 1). Spatial variation in aphid suppression by predators was expressed as the 'variance to mean ratio'; that is, the variance in aphid abundance across the four quadrants scaled to the mean number of aphids remaining $\left(\sigma^{2} /\right.$ mean). I evaluated the impact of predator species richness (No-predator control vs. 1 species vs. 4 species) on (1) total aphid abundance and (2) the variance to mean ratio of aphid abundance across quadrants in two separate analyses of variance (Proc Mixed, SAS version 9.2, SAS 
institute, Cary, NC). To investigate the potential occurrence of intraguild predation, I also evaluated the impact of predator diversity treatment (1 species vs. 4 species) on the number of predators alive after 48 hours using analysis of variance (Proc Mixed, SAS version 9.2, SAS institute, Cary, NC).

Impact of predator diversity on the strength and spatial stability of aphid suppression in field cages

To evaluate the impact of predator species richness on the abundance of and spatial variation in $R$. padi aphid populations over a larger spatial scale and longer duration of time, I conducted a field experiment at the University of Missouri Bradford Farm Research and Extension Center. I released predator communities that varied in species richness into wheat habitats infested with aphids and measured the number of aphids remaining after 4 weeks. Each experimental unit in this study consisted of a $2 \mathrm{~m} \mathrm{x}$ $2 \mathrm{~m} \times 2 \mathrm{~m}$ cage supported by a PVC-frame and covered with 32 x 32 Lumite mesh (Lumite, Inc., Alto, GA) with a zipper on one side to allow for cage entry. The cage bottoms were buried under $\sim 20 \mathrm{~cm}$ of soil to block insect movement into or out of cages. To control for the presence of predatory arthropods that may have been present within field cages prior to the onset of the experiment, I installed plastic pitfall traps $(11.43 \mathrm{~cm} \mathrm{x}$ $7.62 \mathrm{~cm}$ ) filled with soapy water directly into the ground at each of the four corners of the cage. The 4 pitfall traps in each cage were left for 1 week prior to the onset of the experiment, after which all traps were emptied and removed. Each cage housed a plot of 10-day old wheat roughly $0.6 \mathrm{~m} \times 1.2 \mathrm{~m}$ in size, planted into the ground at the center of the cage. Approximately 450 wheat seeds were planted/ plot in each cage. The wheat habitat 
was sub-divided into four equal quadrants, each approximately $0.3 \mathrm{~m} \times 0.6 \mathrm{~m}$ in size (Fig. 3). A total of 200 R. padi aphids were released into one of the quadrants of the wheat plot (randomly on the left or right), and the aphids were allowed unrestricted access to colonize the other three quadrants. The aphids were allowed 24 hours to settle on the host plants and become established before the addition of predators.

Due to the timing of the experiments relative to the phenology of the predators, a slightly different community of predators was available for the field experiment than the greenhouse study. The predators used in the field experiment included the pink-spotted lady beetle (C. maculata), the damsel bug (N. americoferus), the minute pirate bug Orius insidiosus (Say) (Hemiptera: Anthocoridae), the big-eyed bug Geocoris punctipes (Say) (Hemiptera: Geocoridae), and the green lacewing (C. carnea). Larvae of the green lacewing were obtained from Rincon-Vitova Insectaries (Ventura, CA), while other predator species were collected as adults in the field by hand or with a D-vac suction sampler (Rincon-Vitova Insectaries, Ventura, CA). Predator assemblages were created from the pool of five predator species according to three treatments: (1) No-predator control, (2) 1 predator species present or (3) 4 predator species present. The 1-species predator treatment and 4-species predator treatment each included 15 replicates (three replicates of each of the five unique species compositions possible from the pool of 5 predator taxa) and the No-predator control treatment included 6 replicates, for a total of 36 experimental units (Fig. 4). I utilized a substitutive design wherein total predator density across treatments containing predators was held constant at 24 individuals per cage. 
After the 24-hour aphid settling period, predators were released into cages and allowed 4 weeks without disturbance to exert impacts on $R$. padi aphid populations. After 4 weeks, all field cages were exhaustively searched to count the remaining aphids in the four quadrants. Spatial variation in aphid suppression by predators across the four quadrants was again expressed as the 'variance to mean ratio' $\left(\sigma^{2} /\right.$ mean $)$. I evaluated the impact of predator species richness (No-predator control vs. 1 species vs. 4 species) on (1) total aphid abundance and (2) the spatial variation in aphid abundance in two separate analyses of variance (Proc Mixed, SAS version 9.2, SAS institute, Cary, NC). Total aphid abundance was $\log _{10}$ transformed to meet the assumptions of the analysis. Given the complexity of the habitat and the high mobility of the predators used, I did not collect predators at the end of the study.

Observational study of the impact of predator species richness on the location of predators in the habitat

Increasing diversity is predicted to decrease spatial variability in ecosystem function by increasing the similarity of local communities across the landscape (Fukami et al. 2001). To investigate whether increasing predator diversity results in more consistent predator presence across the habitat, I conducted an experiment in the laboratory where I observed the spatial location of predators in response to varying levels of predator species richness. Experimental units were 10-gallon glass terraria (Aqua Culture, Wal-Mart Stores Inc., Bentonville, AR), each containing 5 wheat plants planted directly into soil at the bottom of terraria and arranged in a row. A total of $30 \mathrm{R}$. padi aphids were released into each terrarium and allowed one hour to settle before the addition of predators. 
There were four predator species available at the time of the study that were used to create the predator treatments: the pink-spotted lady beetle $C$. maculata, the minute pirate bug $O$. insidiosus, the damsel bug $N$. americoferus, and the green lacewing $C$. carnea. Predator assemblages were assembled from the pool of four predator species according to two treatments: 1 predator species or 3 predator species present in the assemblage. There were 12 replicates of each treatment (three replicates of each of the four unique species compositions) for a total of 24 experimental units (Fig. 5). I again employed a substitutive design such that total predator density across treatments was held constant at 3 individuals per cage.

Every $6 \mathrm{hr}$ over a 48-hr period, I made visual observations to document the total number of predators alive and the number and location of predators on each of the 5 plants in each terrarium. Spatial variation in predator abundance across the 5 host plants for each observational period was calculated as the variance to mean ratio. The impact of predator species richness (1-species vs. 3-species) on (1) the number of predators alive, (2) the number of predators on plants, and (3) the spatial variance to mean ratio in predator abundance over time was determined by repeated measures analyses of variance (Proc Mixed, SAS version 9.2, SAS institute, Cary, NC). Covariance structures were constructed for each mixed model repeated measures analysis and compound symmetry was determined to be the best-fit model in each case using the Bayesian Information Criterion. The variance to mean ratio of predator abundance was $\log _{10}$ transformed to meet the assumptions of the analysis. 


\section{RESULTS}

Impact of predator diversity on the strength and spatial stability of aphid suppression in greenhouse mesocosms

I found a significant effect of predator diversity treatment on the overall strength of aphid suppression, with the most diverse predator treatment being most effective at controlling aphids (Fig. 6A, $F_{2,33}=9.59, p<0.0005$ ). After 48 hours, the magnitude of aphid suppression when 4 predator species were present was significantly greater than that of the single-species predator treatment $(t=2.66, p=0.036)$. Furthermore, the 4species predator treatment reduced aphid abundances as compared to the No-predator control, while the 1 -species predator treatment did not $(t=4.22, p=0.0005$ and $t=2.21$, $p=0.10$, respectively).

Predator diversity also enhanced the spatial stability of aphid suppression (Fig. $\left.7 \mathrm{~A}, F_{2,32}=8.45, p=0.0011\right)$. I found that the spatial variance to mean ratio of aphid abundance was lowest in the presence of 4 predator species. Aphids were more evenly distributed across the habitat in the presence of the diverse predator guild as compared to the No-predator control or the 1 -species predator treatment $(t=3.82, p=0.001$ and $t=2.84$, $p=0.008$, respectively). The No-predator control and the 1 -species predator treatment exhibited equally high spatial variance in aphid abundance across the habitat $(t=1.62$, $p=0.12$ ). Although aphids were originally released into only one quadrant, in the absence of predators aphids successfully colonized each of the three other quadrants (mean aphid abundance per quadrant $\pm 1 \mathrm{SEM}=54.83 \pm 13.77,34.33 \pm 8.33,6.00 \pm 1.22$, and $2.67 \pm$ $0.80)$. 
When I compared the absolute number of predators remaining in cages at the end of the study, I found that predator survival did not differ between the 1-species predator treatment and the 4 -species predator treatment $(t=0.86, p=0.40$; mean $\pm 1 \mathrm{SEM}=2.87 \pm$ 0.274 , and $2.53 \pm 0.274$, respectively).

Impact of predator diversity on the strength and spatial stability of aphid suppression in field cages

After 4 weeks, I found that increasing predator diversity enhanced the magnitude of aphid suppression in the field (Fig. $6 \mathrm{~B}, F_{2,33}=11.58, p<0.0002$ ). When predators were present, either 1 predator species or 4 predator species, aphid abundance was reduced as compared to the No-predator control $(t=2.87, p=0.022$ and $t=4.75, p=0.0001$, respectively). However, the 4 -species predator treatments were most effective at suppressing aphids, with the magnitude of aphid suppression in these treatments being significantly greater than that of single-species predator treatments $(t=2.50, p=0.0531)$.

In addition to greater overall aphid suppression, increasing predator diversity also enhanced the spatial stability of aphid suppression (Fig. $7 \mathrm{~B}, F_{2,26}=12.76, p=0.0001$ ). The presence of predators decreased the spatial variation in the abundance of aphids across the habitat as compared to when predators were absent and aphid abundance was highly variable from one habitat segment to the next (No-predator control vs. 1 species: $t=2.05$, $p=0.051$; No-predator control vs. 4 species: $t=4.83, p<0.0001)$. Furthermore, spatial variation in aphid abundance was lowest in the presence of the diverse predator assemblage such that aphids occurred more uniformly across the habitat in the presence of 4 predator species than they did in the presence of 1 predator species $(t=3.42$, $p=0.002)$. As in the greenhouse study, aphids were originally released into only one 
habitat quadrant, but in the absence of predators aphids successfully colonized each of the three other quadrants (mean aphid abundance per quadrant $\pm 1 \mathrm{SEM}=395.17 \pm 83.72$, $228.67 \pm 79.05,35.00 \pm 8.44$, and $27.67 \pm 7.99)$.

Observational study of the impact of predator species richness on the location of predators in the habitat

In the 48-hr observational study, I again found that predator survival did not differ between predator diversity treatments (main effect of predator diversity: $F_{1,22}=0.01$, $p=0.94)$. The number of predators alive at the end of the experiment was the same whether 1 or 3 predator species were present (mean \pm 1 SEM: $2.056 \pm 0.18$ and $2.037 \pm$ 0.18 , respectively). Furthermore, the lack of an effect of predator diversity treatment on predator survival was consistent across observational time periods (predator diversity $\mathrm{x}$ time: $\left.F_{8,176}=0.78, p=0.62\right)$.

When I evaluated the location of predators within terraria, I observed that predator diversity treatment significantly influenced the number of predators found on wheat plants (Fig. 8A, main effect of predator diversity: $F_{1,22}=5.42, p=0.030$ ). The total number of predators found per wheat plant was significantly higher in 3-species predator treatments as compared to treatments containing only 1 predator species. Furthermore, the effect of predator diversity on the number of predators per wheat plant did not vary over time (predator diversity $\mathrm{x}$ time: $F_{8,176}=1.85, p=0.072$ ).

Increasing predator diversity also increased the spatial similarity in the abundance of predators foraging on plants across the habitat (Fig. 9B, main effect of predator 
diversity: $\left.F_{1,21}=3.98, p=0.059\right)$ and this effect was consistent across the observational time periods (predator diversity $\mathrm{x}$ time: $F_{8,127}=1.62, p=0.13$ ).

\section{DISCUSSION}

While many studies have explored the impact of the loss of predator diversity on the sign and strength of prey suppression (Letourneau et al. 2009, Finke and Snyder 2010, Tylianakis and Romo 2010), few have considered predator diversity effects on the stability of this ecosystem service provided by predators. Studies that do address the relationship between predator diversity and stability tend to focus on the temporal variation in prey abundance, whereas spatial stability has received much less attention (Thébault and Loreau 2005, Griffin and Silliman 2011). In both the greenhouse and the field, my studies revealed that herbivore suppression was both greater in magnitude and more spatially stable when species-rich predator communities were present, as compared to only single-species predator assemblages (Figs. $6 \&$ 7). Therefore, increasing predator diversity has the potential to enhance the strength and predictability of prey suppression by natural enemies across the landscape.

Overall, the greater magnitude of aphid suppression by the diverse predator assemblage may have been due to complementarity in resource use, with predator species

partitioning their use of the prey resource and thus consuming more total prey (Losey and Denno 1998b, Finke and Snyder 2008). Positive relationships between predator diversity and aphid suppression due to complementarity have been documented in other systems using very similar predator species as those used here (Snyder et al. 2006, Steffan and Snyder 2010). For example, lady beetles and damsel bugs may forage on different parts 
of the plant, resulting in lower interspecific competition relative to intraspecific competition, and an overall benefit to aphid suppression of increasing diversity (Straub and Snyder 2008). My finding of greater overall abundance of predators on plants at higher predator species richness supports the idea that different predator species partition their foraging environment, thereby reducing competition and resulting in more predators on plants (Steffan and Snyder 2010). However, it is also possible that the greater magnitude of suppression at higher levels of diversity was due to the greater probability of including a particularly voracious predator at higher levels of diversity (i.e. an identity effect) (Huston 1997, Wardle 1999, Cardinale et al. 2006, Chapter 3).

The greater spatial predictability in aphid abundance across the habitat may have arisen via a variety of mechanisms. Aphids were originally released into only one quadrant of the wheat habitat and then allowed to freely colonize the remaining quadrants. Therefore, although aphids colonized all quadrants, there was inherent variation in aphid abundance across the habitat. Predators may aggregate in areas of high prey abundance, resulting in greater local suppression of prey in high density 'hotspots'. Using a diverse guild of lady beetle predators and their aphid prey, Cardinale et al. (2006) found that diverse lady beetle guilds were more likely to occur in patches of high prey density. Furthermore, after a period of several days, diverse lady beetle guilds effectively reduced aphid densities not only at the local site of high density, but also across habitat patches. Density-dependent suppression of aphids by diverse predator communities in my study could have contributed to greater spatial consistency in aphid abundance. However, my observational laboratory study provides no evidence that increasing predator diversity enhanced predator aggregation. Instead, I found that as predator diversity increased, the 
spatial variability in the abundance of predators across host plants decreased (Fig. 8).

This supports the idea that diversity promoted spatial homogeneity in herbivore abundance by increasing the compositional similarity of the predator community across the habitat (Fukami et al. 2001). However, I do not know whether the impact of predators on the distribution of aphids was mediated by the consumption of prey by predators or the dispersal and re-distribution of prey in response to the threat of predation.

There is increasing concern that the loss of predator diversity will lead to more frequent and unpredictable herbivore outbreaks, particularly in intensively-managed agroecosystems where predator abundance and diversity is consistently lower than in more diverse cropping or natural systems (Crowder et al. 2010, Krauss et al. 2011, Thies et al. 2011). My results show that conservation biological control approaches, with the goal of protecting and enhancing natural enemies, can have valuable benefits for both the overall magnitude of herbivore suppression and the predictability of herbivore suppression across the habitat. This spatial reliability of herbivore suppression by predators can be critical in agroecosystems, where herbivore populations are often patchy and yield losses due to insect feeding can be costly (Losey and Vaughan 2006). Furthermore, when the herbivore in question is a vector of a plant pathogen, predator diversity also has the potential to influence plant disease risk by reducing herbivore abundance and spatial variability. For vector-borne plant pathogens, the spatial distribution of vector organisms and their encounters with hosts may be even more important for the occurrence of disease than the absolute number of vectors in the habitat (Keesing et al. 2006). Therefore, I conclude that management strategies that preserve predator diversity have the potential to decrease the frequency and unpredictability of 
herbivore outbreaks, with cascading positive effects on plant yield and health (Cardinale et al. 2003). By influencing the stability of ecosystem services and functions in time and/or space, biodiversity can have important consequences for the persistence of ecosystems. 
Table 1. Detection probability of bird cherry-oat aphids (Rhopalosiphum padi) on wheat plants at set time intervals after aphid release.

\begin{tabular}{|c|c|c|c|}
\hline Time interval & \# R. padi released & $\begin{array}{c}\text { \# R. padi detected } \\
\text { after time interval }\end{array}$ & $\begin{array}{c}\text { Detection } \\
\text { probability (\%) }\end{array}$ \\
\hline 15 minutes & 40 & 38 & $95 \%$ \\
\hline 30 minutes & 40 & 39 & $97.5 \%$ \\
\hline 1 hour & 40 & 39 & $97.5 \%$ \\
\hline 6 hours & 40 & 38 & $95 \%$ \\
\hline
\end{tabular}




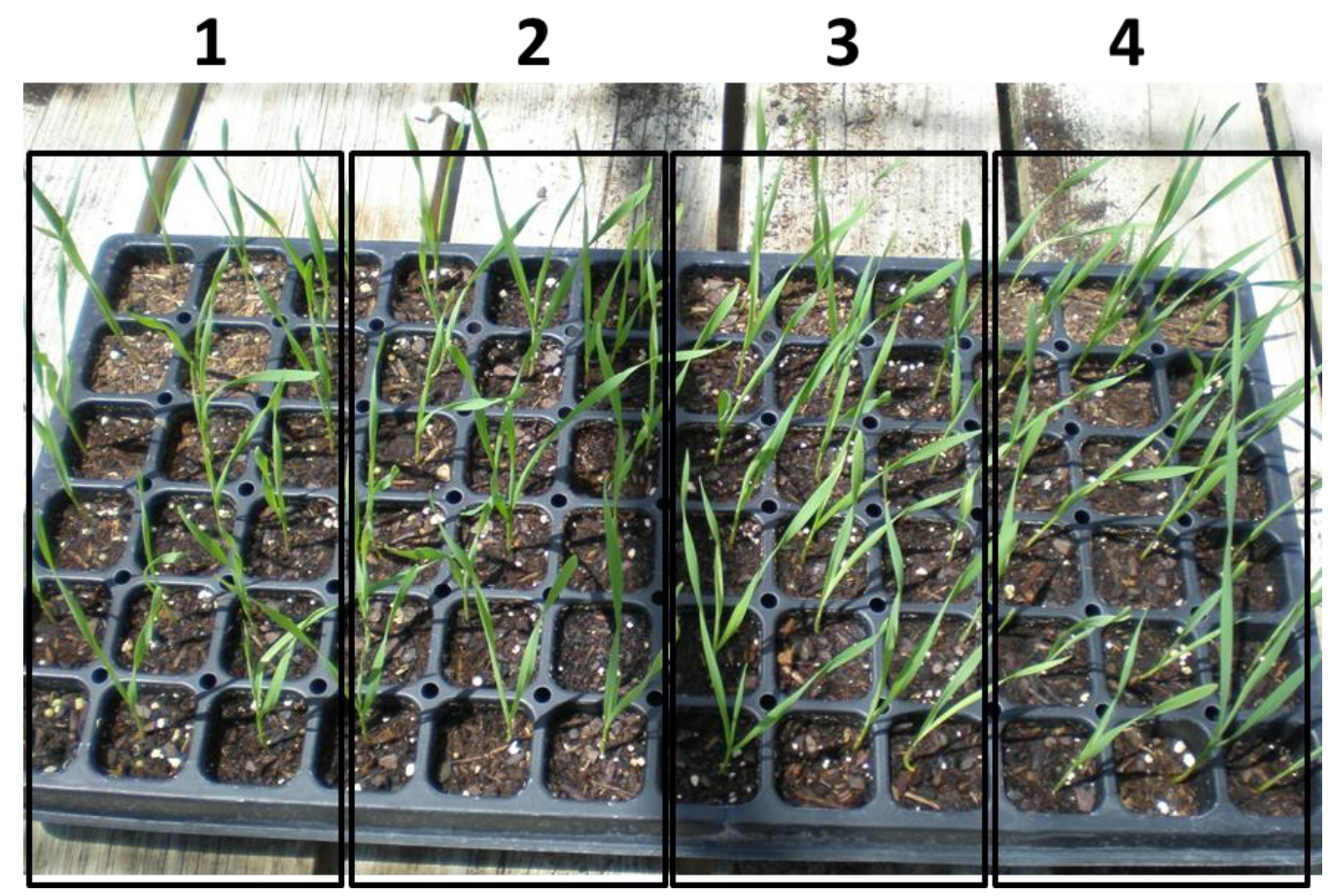

Figure 1. Arrangement of the wheat habitat in each greenhouse mesocosm. Each tray consisted of 72 wheat plants in a $12 \times 6$ design. For the purposes of evaluating aphid distribution, the habitat was further divided into 4 equal sections (numbered 1-4), with segment 1 being the closest and 4 the most distal from the site of initial aphid release. 


\begin{tabular}{|c|c|c|c|c|c|c|}
\hline Control & 6 & & & & & \\
\hline 1-species & 3 & $\mathbf{x}$ & & & & \\
\hline 1-species & 3 & & $\mathbf{x}$ & & & \\
\hline 1-species & 3 & & & $\mathbf{x}$ & & \\
\hline 1-species & 3 & & & & $\mathbf{x}$ & \\
\hline 1-species & 3 & & & & & $x$ \\
\hline 4-species & 3 & $\mathbf{x}$ & $\mathbf{x}$ & $\mathbf{x}$ & $x$ & \\
\hline 4-species & 3 & $\mathbf{x}$ & $\mathbf{x}$ & $x$ & & $x$ \\
\hline 4-species & 3 & $\mathbf{x}$ & $x$ & & $x$ & $x$ \\
\hline 4-species & 3 & $\mathbf{x}$ & & $x$ & $\mathbf{x}$ & $x$ \\
\hline 4-species & 3 & & $\mathbf{x}$ & $\mathbf{x}$ & $\mathbf{x}$ & $x$ \\
\hline
\end{tabular}

Figure 2. Natural enemy species combinations used to create treatment replicates in greenhouse mesocosms. An "x" denotes the presence of a predator species in that particular treatment replicate. 


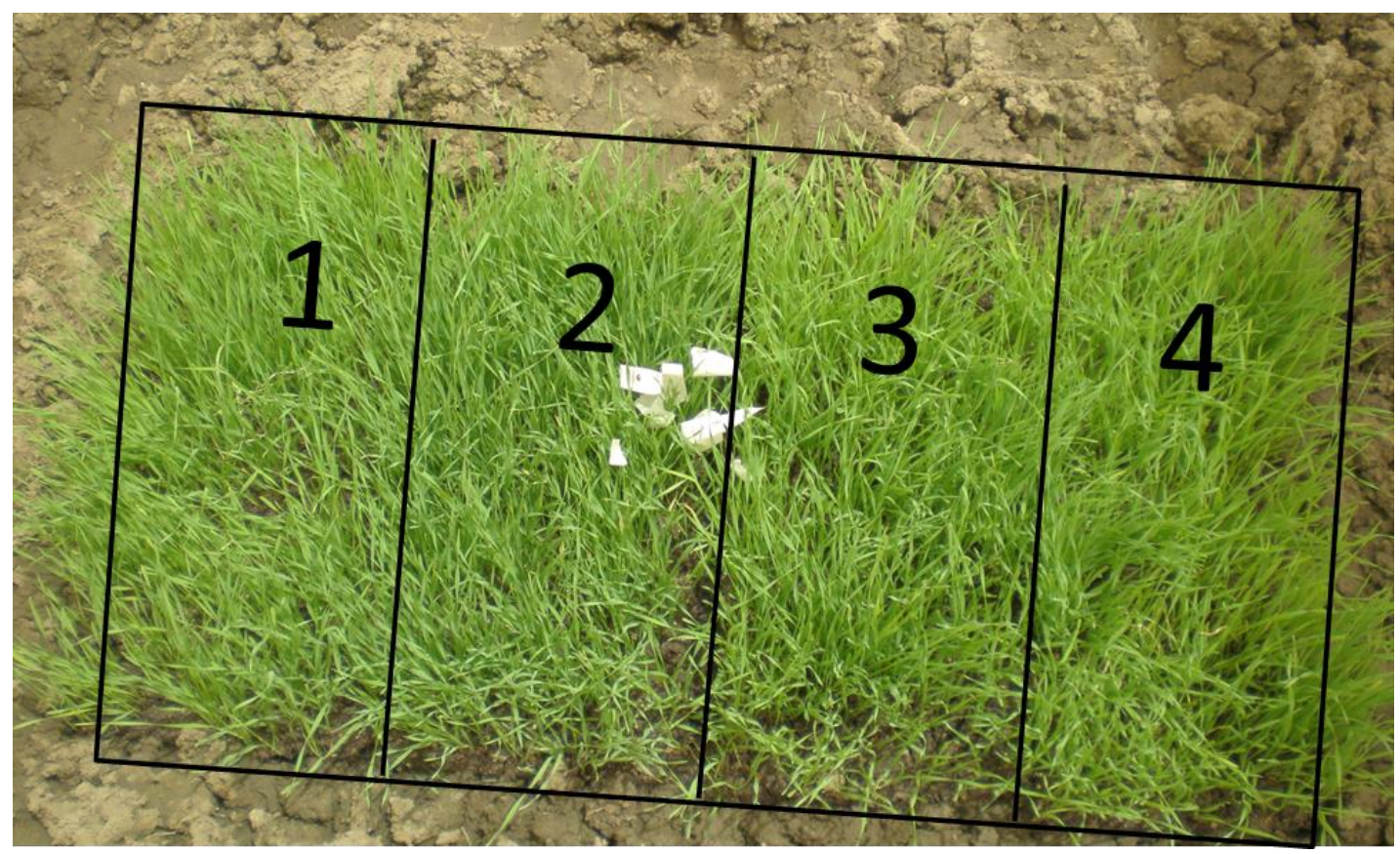

Figure 3. Arrangement of the wheat habitat in each field cage. Each wheat plot consisted of approximately 450 plants. For the purposes of evaluating aphid distribution, the habitat was divided into 4 equal sections (numbered 1-4), with segment 1 being the closest and 4 the most distal from the site of initial aphid release. 


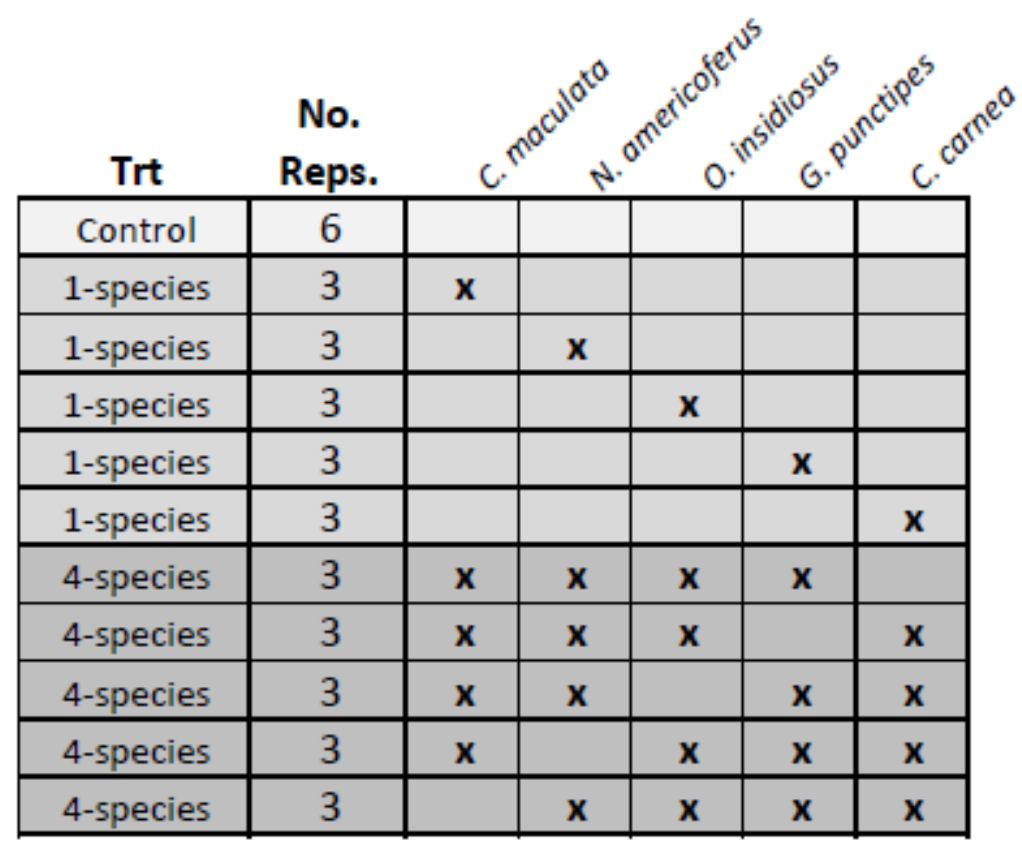

Figure 4. Natural enemy species combinations used to create treatment replicates in field cages. An " $x$ " denotes the presence of a predator species in that particular treatment replicate. 


\begin{tabular}{|c|c|c|c|c|c|}
\hline No. & \multicolumn{5}{c|}{ Reps. } \\
\hline Control & 6 & & & & \\
\hline 1-species & 3 & $\mathbf{x}$ & & & \\
\hline 1-species & 3 & & $\mathbf{x}$ & & \\
\hline 1-species & 3 & & & $\mathbf{x}$ & \\
\hline 1-species & 3 & & & & $\mathbf{x}$ \\
\hline 4-species & 3 & $\mathbf{x}$ & $\mathbf{x}$ & $\mathbf{x}$ & \\
\hline 4-species & 3 & $\mathbf{x}$ & $\mathbf{x}$ & & $\mathbf{x}$ \\
\hline 4-species & 3 & $\mathbf{x}$ & & $\mathbf{x}$ & $\mathbf{x}$ \\
\hline 4-species & 3 & & $\mathbf{x}$ & $\mathbf{x}$ & $\mathbf{x}$ \\
\hline
\end{tabular}

Figure 5. Natural enemy species combinations used to create treatment replicates in laboratory terraria. An " $x$ " denotes the presence of a predator species in that particular treatment replicate. 

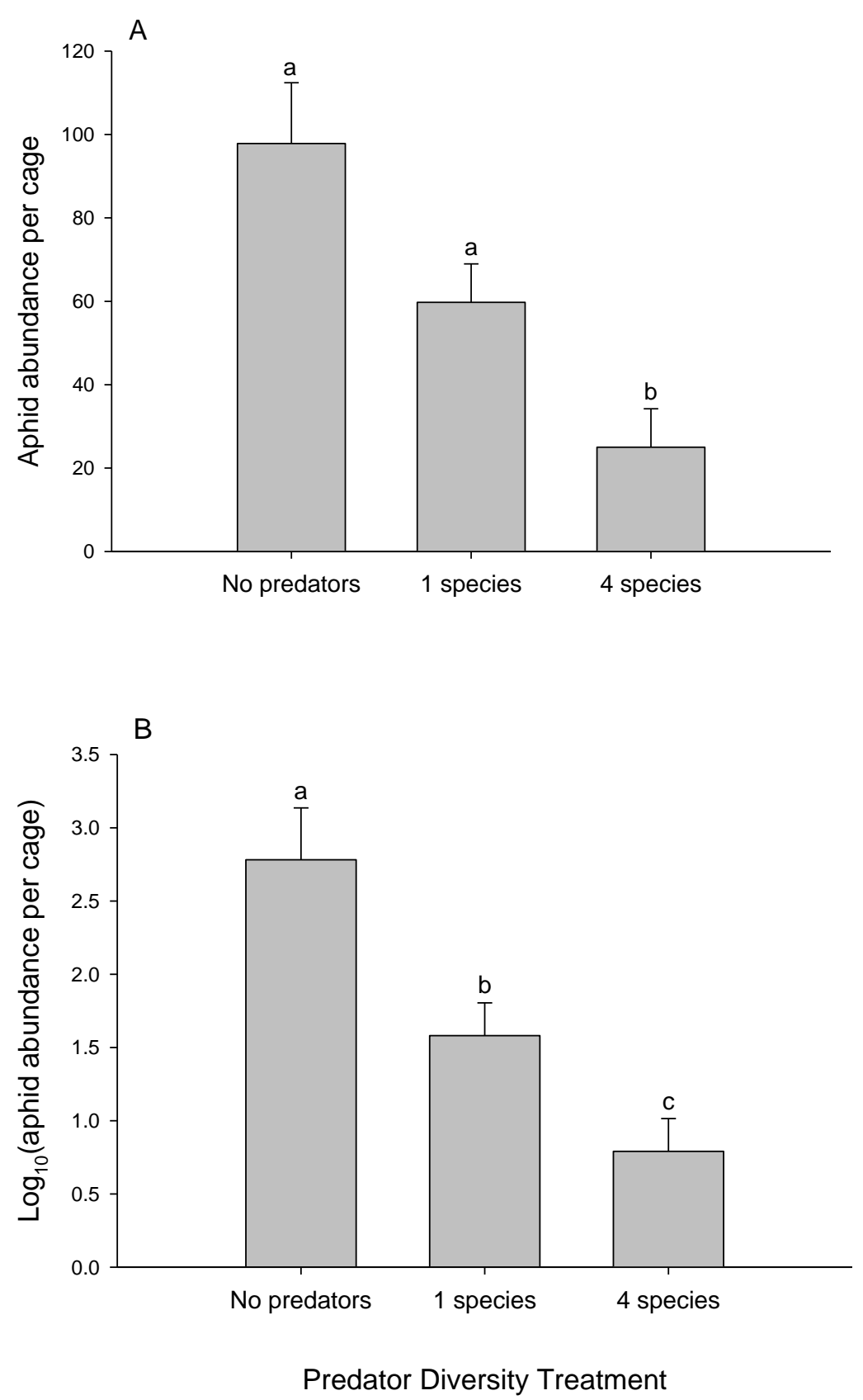

Figure 6. The effect of increasing predator species richness on bird cherry-oat aphid (Rhopalosiphum padi) abundance in (A) greenhouse mesocosms after 48 hours, and (B) field cages after 4 weeks. LSmeans \pm 1 SEM with different letters are significantly different at the $p<0.05$ level. 

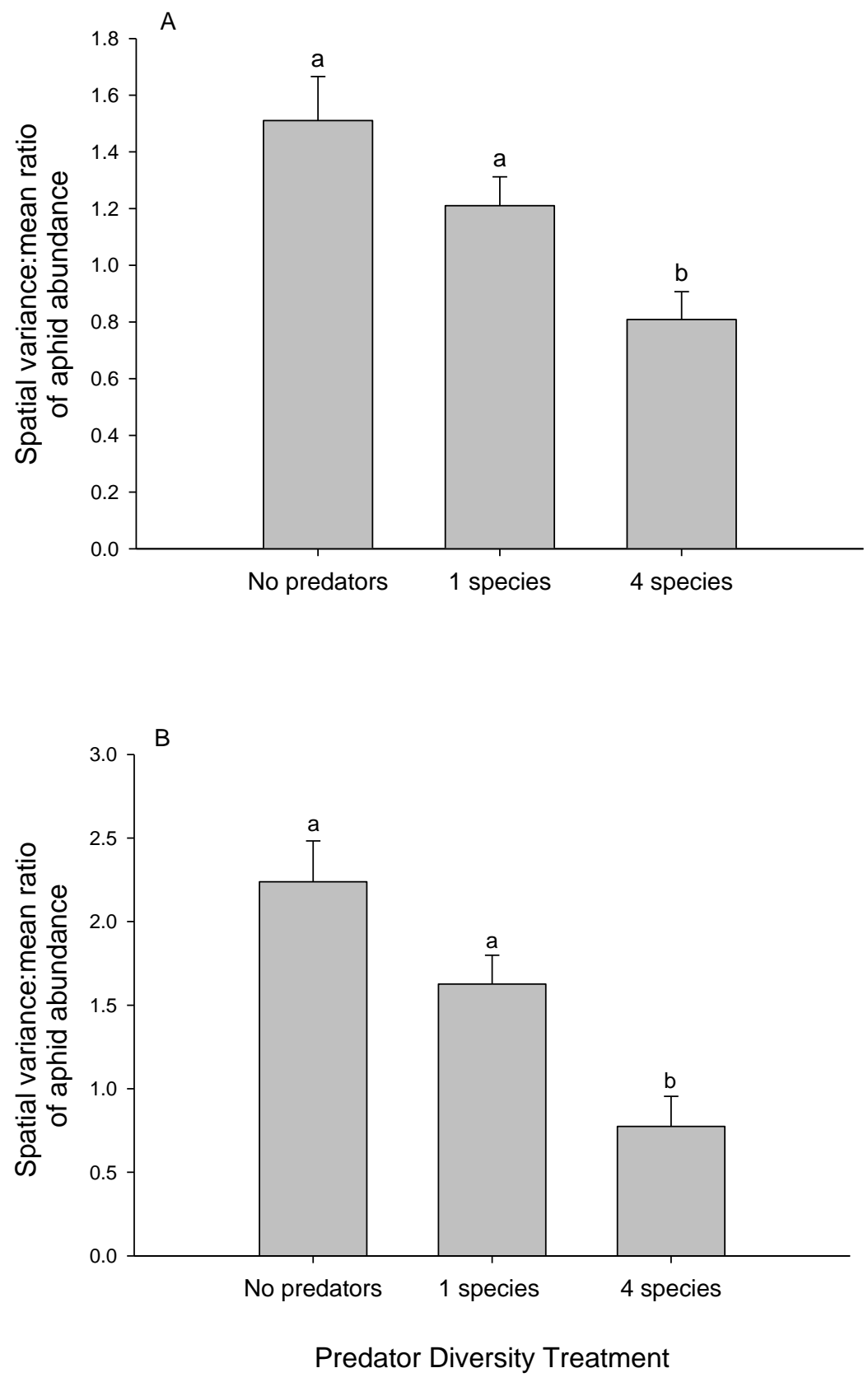

Figure 7. The effect of increasing predator species richness on the spatial stability (variance to mean ratio) of bird cherry-oat aphid (Rhopalosiphum padi) abundance across habitat quadrants in (A) greenhouse mesocosms after 48 hours, and (B) field cages after 4 weeks. LSmeans \pm 1 SEM with different letters are significantly different at the $p<0.05$ level. 

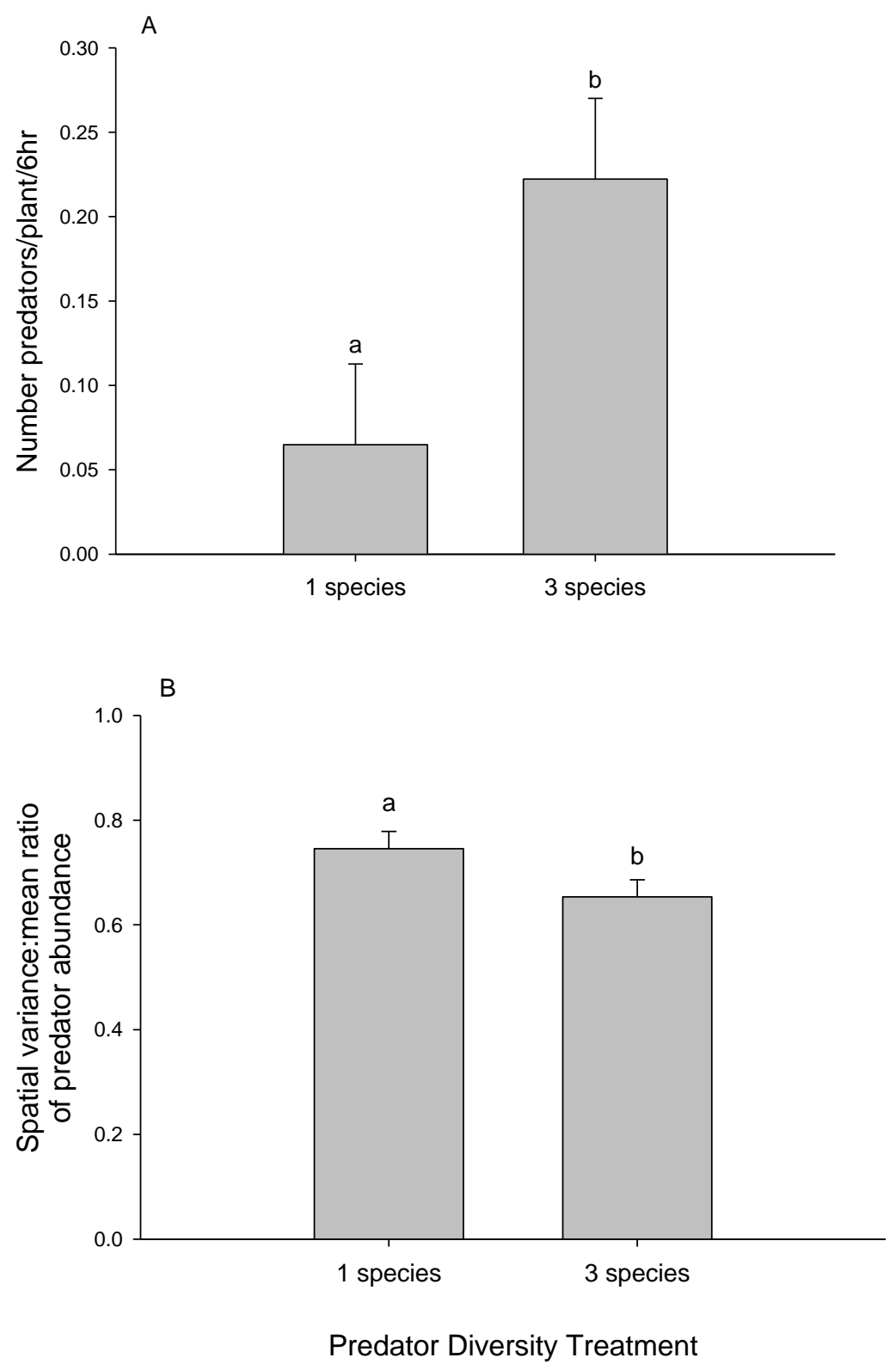

Figure 8. The effect of predator species richness on (A) the average number of predators (out of 4) observed per plant and (B) the spatial stability (variance to mean ratio) in the abundance of predators across 5 wheat plants, during a 48-hr observational study. LSmeans \pm 1 SEM with different letters are significantly different at the $p<0.05$ level. 


\title{
CHAPTER 3.
}

\section{THE CONTRIBUTION OF PREDATOR IDENTITY TO THE SUPPRESSION OF HERBIVORES BY A DIVERSE PREDATOR} ASSEMBLAGE

\begin{abstract}
As our understanding of the consequences of biodiversity loss for ecosystem services and functions has developed, the focus of studies has shifted from describing the sign and shape of the relationship to identifying the specific mechanisms contributing to the outcome. Studies investigating the importance of predator diversity for natural pest suppression have found that enhancing predator diversity often increases the strength of prey suppression. However, the underlying mechanisms vary from 'true' benefits of diversity that require the presence of multiple species to 'apparent' benefits of diversity that result from the inclusion of one dominant species, with very different implications for conservation and management in each case. In a field experiment, I simultaneously manipulated the species richness and the species composition of a community of commonly-occurring predators of bird cherry-oat aphids (Rhopalosiphum padi) in wheat (Trticum aestivum). I found that on average herbivore suppression was greater in the presence of a species-rich predator assemblage as compared to singlespecies predator assemblages. When investigating the mechanism behind this response, I found that species compositions containing the lady beetle Coleomegilla maculata outperformed those assemblages lacking the beetle, suggesting that the presence of this one dominant predator played a key role. This conclusion was supported by the fact that
\end{abstract}


C. maculata lady beetles effectively suppressed aphid populations across a range of beetle densities in the greenhouse. My results suggest that species composition and identity are critical factors to consider in efforts to conserve valuable ecosystem services, and that conservation efforts targeting the key lady beetle predator would provide the most effective natural biological control of bird cherry-oat aphids in wheat.

\section{INTRODUCTION}

The current level of human-mediated environmental modification, including habitat fragmentation and destruction, exotic species introduction, and global climate change, promotes species extinctions and threatens biodiversity at a global scale (Tilman et al. 1994, Vitousek et al. 1997, Burney and Flannery 2005). As a result, the role of biodiversity in the dynamics of ecosystems has emerged as an area of avid research and interest (Altieri 1999, Loreau et al. 2001, Hooper et al. 2005, Srivastava and Vellend 2005, Reiss et al. 2009). Studies in a wide variety of systems have demonstrated that altered biodiversity impacts valuable ecosystem services like primary production, pollination, resistance to invasion, and natural pest/pathogen suppression (Power 1991, Hector et al. 1999, Knops et al. 1999, Kennedy et al. 2002, Stachowicz et al. 2002, LoGiudice et al. 2003, Snyder et al. 2006, Straub and Snyder 2008, Van Der Heijden et al. 2008, Ramirez and Snyder 2009, Jabbour et al. 2011, Garibaldi et al. 2013). While the sign and magnitude of the impact of diversity loss can vary across systems and services investigated, meta-analyses reveal that overall the relationship is positive with an increase in species richness predicted to enhance ecosystem functioning (Balvanera et al. 2006, Cardinale et al. 2006, Worm et al. 2006). 
Although most biodiversity studies have focused on plants and their consumers, organisms feeding at higher trophic levels such as predators are predicted to be at greater risk of extinction than more basal species (Duffy 2003, Dobson et al. 2006). This is particularly evident in intensively-managed agroecosystems where predator abundance and diversity is consistently lower than in more diverse cropping or natural systems (Crowder et al. 2010, Krauss et al. 2011, Thies et al. 2011). The loss of predator diversity is significant because predators play an economically important role as agents of natural pest suppression (Losey and Vaughan 2006). Thus, declines in the abundance or diversity of predator species could have important implications for the management of herbivore pests, as well as cascading effects on plant yield (Cardinale et al. 2003). Manipulation of predator species richness has yielded a spectrum of results ranging from no response, to positive or negative impacts on natural pest suppression, with the majority of studies documenting a positive relationship (Cardinale et al. 2006, Bruno and Cardinale 2008, Finke and Snyder 2010, Tylianakis and Romo 2010).

Positive relationships between diversity and natural pest suppression can arise from a variety of mechanisms, including 1) complementarity in resource use among species, with predator species partitioning the type of prey they attack and/or hunting in different locations, 2) facilitation of resource capture, with the rate of prey capture by one predator species increasing in the presence of another species, and 3) identity effects, (a.k.a. sampling effects) whereby more diverse communities are more likely by chance to contain a particularly effective predator species (Ives et al. 2005, Schmitz 2007, Bruno and Cardinale 2008, Finke and Snyder 2010). Mechanisms such as complementarity and facilitation are generally accepted as 'true' benefits of diversity because multiple predator 
species always outperform a single species (Soluk and Collins 1988, Kotler et al. 1992, Petchey 2003). The biological significance of identity effects, on the other hand, is debated. Some have argued that identity effects represent a 'true' benefit of diversity, since natural communities that are more diverse are also more likely to contain particularly effective species (Tilman 1997). However, others argue that the identity effect is merely an 'apparent' benefit of diversity, since greater performance is the result of a single high performing species and not an emergent property of the presence of multiple species (Huston 1997, Wardle 1999, Hooper and Dukes 2004).

Identifying the mechanism behind a positive effect of predator diversity on prey suppression can be tricky. Typically, explicit documentation of the underlying diversity mechanism requires a comparison of the performance of a particular species when part of a diverse mixture to the performance of the same species when in monoculture (Loreau and Hector 2001). This approach works well for plants, in which species performance is measured as biomass and is therefore easily compared across treatments (Hooper et al. 2005). Predator diversity studies, on the other hand, are typically conducted over a timeframe encompassing $\leq 1$ predator generation. Therefore, identity effects in this case do not emerge due to a single predator species numerically dominating a treatment through increased predator reproduction, but instead due to a single predator species dominating the consumption of prey. For predators, however, it can be extremely difficult to quantify predation by individual predator species embedded within multi-species assemblages unless direct observations of every attack are made. Therefore, it is generally assumed that identity effects may be operating if prey consumption by a diverse predator assemblage does not exceed what the most efficient predator species is able to 
accomplish on its own (Petchey 2003, Cardinale et al. 2006, Straub and Snyder 2006, Douglass et al. 2008, Finke and Snyder 2010). However, most predator biodiversity studies manipulate predator diversity while maintaining a constant predator density (i.e. a substitutive or replacement design), resulting in fewer individuals of a given species present in diverse mixtures than monocultures (Ives et al. 2005, Schmitz 2007, Finke and Snyder 2010, Tylianakis and Romo 2010). Therefore, given this experimental design, an identity effect emerges when a particularly effective predator species increases its consumption rate at higher species diversity due to a release from intraspecific competition. This may, in fact, be the case if the dominant predator species over-exploits the prey resource in monoculture and experiences a release from intraspecific competition at lower predator densities in the high diversity treatment.

In this study, I evaluated the impact of predator species richness on the suppression of bird cherry-oat aphids (Rhopalosiphum padi L.) (Hemiptera: Aphididae) in wheat (Triticum aestivum L.). Wheat is one of many economically important species of cereal grains that are grown agriculturally throughout the world (Joseph 2011). Bird cherry-oat aphids are an important pest of cereal grains in part due to their ability to reduce plant quality through the extraction of nutrients, but more importantly due to their role as vectors of generalist plant-pathogens like the cereal and barley yellow dwarf viruses. A diverse guild of aphid natural enemies have been shown to suppress cereal aphid populations in grain crops, including insects from the families Anthocoridae (Hemiptera), Lygaeidae (Hemiptera), Nabidae (Hemiptera), Chrysopidae (Neuroptera), Coccinellidae (Coleoptera), and Braconidae (Hymenoptera) (Kring et al. 1985, Rice and Wilde 1988, Schmidt et al. 2003, Schmidt et al. 2004). Using this system, I tested the 
hypothesis that increasing predator diversity will enhance the strength of herbivore suppression. Furthermore, I attempted to elucidate the mechanism(s) underlying any observed impacts of predator diversity on aphid suppression by examining the contribution of one particularly voracious predator species in more detail. My hope is that by quantifying the relationship between predator diversity and aphid suppression and understanding the underlying mechanism I can contribute to more effective conservation biological control strategies.

\section{MATERIALS \& METHODS}

\section{Effect of predator species richness on aphid abundance: Field experiment}

To assess the impact of predator diversity on the strength of aphid suppression, I released predator communities that varied in species richness and composition into wheat habitats infested with aphids and measured aphid abundance after 4 weeks. Each experimental unit consisted of a $2 \mathrm{~m} \times 2 \mathrm{~m} \times 2 \mathrm{~m}$ mesh cage supported by a PVC-frame and covered with 32 x 32 Lumite mesh (Lumite, Inc., Alto, GA) with a zipper on one side to allow for cage entry. The cage bottoms were buried under $\sim 20 \mathrm{~cm}$ of soil to block insect movement into or out of cages. Each cage housed a plot of 10-day old wheat $0.6 \mathrm{~m} \times 1.2 \mathrm{~m}$ in size. The wheat was germinated in the greenhouse and then transplanted into the ground at the center of the cage (Fig. 3). A total of 200 bird cherry-oat (R. padi) aphids were released into the wheat plot and allowed 24 hours to become established before the addition of predators. I used the following 5 generalist predator species, which occurred commonly based on visual counts made in wheat fields: the pink-spotted lady beetle Coleomegilla maculata (DeGeer) (Coleoptera: Coccinellidae), the damsel bug Nabis 
americoferus (Carayon) (Hemiptera: Nabidae), the minute pirate bug Orius insidiosus (Say) (Hemiptera: Anthocoridae), the big-eyed bug Geocoris punctipes (Say) (Hemiptera: Geocoridae), and the green lacewing Chrysoperla carnea (Stephens) (Neuroptera: Chrysopidae). Green lacewing larvae were obtained from Rincon-Vitova Insectaries (Ventura, CA), while all other predator species were collected as adults in the field by hand or via a D-vac suction sampler (Rincon-Vitova Insectaries, Ventura, CA). Predator assemblages were created from the pool of 5 predator species according to three treatments: (1) No-predator control, (2) 1 predator species present or (3) 4 predator species present. Species composition varied within each predator diversity treatment such that the 1-species treatment consisted of each of the five predator species alone and the 4species treatment consisted of each of the five possible combinations of four predator species from the pool of five predator taxa (Fig. 4). The 1-species and 4- species predator treatments each included 15 replicates (three replicates of each of the five unique species compositions) and the No-predator control included 6 replicates, for a total of 36 experimental units. After the 24-hour aphid settling period, predators were released into cages and allowed 4 weeks without disturbance to exert impacts on aphid populations. After this time, the entire wheat plot in each cage was visually searched and the remaining aphids counted.

I employed a substitutive design such that total predator density across treatments containing predators was held constant at 24 individuals per cage. As a result, the 4species predator treatments received $1 / 4^{\text {th }}$ the number of individuals of each predator species as compared to the 1 -species predator treatments ( 6 versus 24 individuals of each predator species respectively). Given this experimental design, for an identity effect to 
emerge (i.e. a finding of no difference in prey consumption between the diverse predator assemblage and the most efficient predator monoculture), 6 individuals of the efficient predator species in the high diversity treatment would need to be just as effective at aphid suppression as the 24 individuals in the 1 -species treatment.

The impact of predator diversity treatment (No-predator control vs. 1 predator species vs. 4 predator species) on aphid abundance was determined by analysis of variance (Proc Mixed, SAS version 9.2, SAS institute, Cary, NC). To further explore whether any observed effect of predator diversity on aphid abundance was due to an identity effect or a true benefit of diversity, I conducted 10 pre-planned contrasts comparing 1) aphid abundance in each of the five unique 1-species predator compositions to the average of the 4-species predator treatment and 2) aphid abundance in each of the five unique 4-species predator compositions to the average of the 1-species predator treatment (Proc Mixed, SAS version 9.2, SAS institute, Cary, NC). The data were $\log _{10}$ transformed to meet the assumptions of the analyses. If aphid suppression by a particular predator species alone was not different from the average aphid suppression by 4 predator species, then the identity effect was implicated. If aphid suppression by a particular set of 4 predator species was not different from the average aphid suppression when 1 predator species was present, identity effects were again implicated.

Impact of predator species identity on aphid abundance: Greenhouse experiment

Based on the results of the field experiment, the pink-spotted lady beetle $C$. maculata appeared to be a key predator species influencing a pattern of enhanced aphid suppression in species-rich predator assemblages. To further investigate whether $C$. maculata beetles are a dominant predator species contributing to an identity effect, I 
compared suppression of aphids by $C$. maculata beetles across a range of beetle densities and in environments where aphids were limiting or not limiting.

The experimental units were $60 \mathrm{~cm} \times 60 \mathrm{~cm} \times 60 \mathrm{~cm}$ bug dorm insect cages (MegaView Science Co., Ltd., Taichung, Taiwan) housed at the University of Missouri Ashland Road greenhouse facility $\left(16: 8 \mathrm{~L}: \mathrm{D}, 22-23^{\circ} \mathrm{C}\right)$. Each cage contained a single tray of 10-day old wheat plants arranged in a $6 \times 12$ grid for a total of 72 wheat plants per cage. Given that the availability of prey resources can mediate the degree of intraspecific competition between predators (Evans 1991, Hironori and Katsuhiro 1997, Obrycki et al. 1998), I conducted two independent experiments to evaluate the impact of increasing beetle density on aphid suppression at both 'low' and 'high' aphid densities. Initial bird cherry-oat (R. padi) aphid densities were 200 aphids per cage in the first experiment and 400 aphids per cage in the second experiment. In each experiment, aphids were allowed 24-hours to become established before the addition of beetle treatments. There were 4 beetle density treatments: 0, 1, 2, or 4 adults present. Each density treatment was replicated 6 times for a total of 24 experimental units in each experiment. I chose $C$. maculata beetle densities to scale with the beetle densities used in my larger-scale field experiment.

The impact of beetle density $(0,1,2$, or 4 beetle adults $)$ on aphid abundance was assessed by analysis of variance (SAS version 9.2, SAS institute, Cary, NC) for the two experiments independently, one at low aphid density and the other at high aphid density. Pairwise comparisons of treatment means were conducted with Bonferroni adjustments to correct for multiple comparisons. I predicted that if the $C$. maculata beetle is a dominant species contributing to an identity effect, at low aphid density with limiting resources, 1 
beetle individual will be as effective as 4 beetle individuals because aphid consumption by beetles is limited by intraspecific competition. On the other hand, when aphid densities are high and prey are not limiting, 4 beetle individuals will consume more aphids than 1 individual.

\section{RESULTS}

\section{Effect of predator species richness on aphid abundance: Field experiment}

Predator diversity treatment had a significant impact on aphid suppression in field cages after 4 weeks (Fig. 9, $F_{2,33}=11.58, p<0.0002$ ). Both 1 -species and 4 -species predator treatments reduced aphid abundances significantly as compared to the Nopredator control (No-predator control vs. 1 -species average: $t=2.87, p=0.007$; Nopredator control vs. 4 -species average: $t=4.75, p<0.0001)$. On average, the 4 -species predator treatment was found to be more effective than the 1-species predator treatment in aphid suppression (1-species average vs. 4-species average: $t=2.50, p=0.018$ ).

When evaluating the impact of the five unique 1-species predator compositions, I found that two predator species, the pink-spotted lady beetle $C$. maculata and the damsel bug $N$. americoferis, were just as effective as the average of the 4-species predator treatment in suppressing aphid populations (Fig. $9 ; F_{1,25}=0.43, p=0.52$ and $F_{1,25}=0.09$, $p=0.77$, respectively). Aphid suppression was weaker than the average of the 4 -species predator treatment in the presence of the big-eyed bug G. punctipes and the green lacewing $C$. carnea, $\left(F_{1,25}=4.34, p=0.048\right.$ and $F_{1,25}=11.33, p=0.0025$, respectively), and was moderately weaker in the presence of the minute pirate bug $O$. insidiosus $\left(F_{1,25}=3.30\right.$, $p=0.081$ ). When evaluating the effectiveness of the five unique 4-species predator 
compositions, I found that the diverse composition lacking the $C$. maculata beetle was clearly no more effective at aphid suppression than the average of the 1-species treatments (Fig. $9 ; F_{1,25}=0.13, p=0.72$ ). The four remaining species-rich predator compositions, in which $C$. maculata was present, had a tendency to outperform the average of the monocultures, significantly so $(p<0.05)$ in the case of the diverse composition lacking the big-eyed bug $G$. punctipes $\left(F_{1,25}=5.55, p=0.026\right)$ and with moderate significance $(p<0.15)$ for the compositions lacking the damsel bug $N$. americoferis, the minute pirate bug $O$. insidiosus, or the green lacewing $C$. carnea $\left(F_{1,25}=2.46, p=0.13 ; F_{1,25}=2.68, p=0.11 ;\right.$ and $F_{1,25}=2.89, p=0.10$, respectively $)$. Therefore, I observed a general trend whereby 4-species predator compositions containing $C$. maculata beetles were more effective in aphid suppression than the one species-rich predator composition from which $C$. maculata beetles were absent. Given the consistently high performance of 1 -species and 4-species treatments containing $C$. maculata beetles, I thought maybe these beetles were contributing to an identity effect and thus I examined the impact of these beetles on $R$. padi abundance in follow-up experiments.

Evaluating the impact of predator species identity on aphid abundance: Greenhouse experiment

When I evaluated the impact of $C$. maculata beetles on $R$. padi aphids at low density, I found that increasing beetle density had a significant effect on the number of aphids remaining in wheat habitats (Fig. $10 \mathrm{~A}, F_{3,20}=7.77, p=0.0012$ ). Two or four beetles significantly reduced the number of aphids present compared to the no-beetle control (Fig. 10A; $t=3.85, p=0.006$ and $t=4.38, p=0.0017$, respectively), however aphid 
suppression did not differ between 1, 2 or 4-beetle density treatments (Fig. 10A; 1 vs. 2 beetles: $t=1.63, p=0.72 ; 1$ vs. 4 beetles: $t=2.16, p=0.26 ; 2$ vs. 4 beetles: $t=0.53, p=1.00)$. When I manipulated C. maculata density in mesocosms where aphids were at high density, I again found an overall impact of beetle density on the number of aphids remaining in wheat habitats (Fig. $10 \mathrm{~B}, F_{3,20}=5.58, p=0.006$ ). The magnitude of aphid suppression was greatest in the presence of 4 beetles, which was the only treatment to reduce the aphid population as compared to the no-beetle control (Fig. 10B; control vs. 4 beetles: $t=3.83, p=0.0063$ ). Furthermore, 4 beetles were more effective than 1 but no better than 2 beetles in reducing aphid abundance in wheat habitats (Fig. 10B; $t=3.16$, $p=0.030$ and $t=2.24, p=0.22$, respectively).

\section{DISCUSSION}

Previous studies of predator diversity effects on natural pest suppression have revealed a spectrum of results in which the benefit of a diverse predator guild has been attributed to mechanisms such as complementarity or facilitation in prey use by multiple predator species ('true' benefits of diversity) (Kotler et al. 1992, Losey and Denno 1998b, Cardinale et al. 2002) or identity effects, whereby the presence of key predator species drives the success of diverse predator guilds (an 'apparent' benefit of diversity) (Huston 1997, Wardle 1999, Hooper and Dukes 2004). My studies in wheat habitats revealed an overall pattern of greater natural pest suppression when predator assemblages were more species-rich (Fig. 4). However, examination of the performances of individual species compositions suggests that the mechanism behind this benefit of enhanced predator diversity is likely to be species identity, or the presence of a key, productive species 
within diverse predator guilds. Specifically, I found that the pink-spotted lady beetle $C$. maculata was a particularly voracious predator that was, by itself, capable of reducing aphid populations as effectively as diverse assemblages. Furthermore, there was no benefit of diversity in the 4 -species predator composition where C. maculata was absent, resulting in a level of aphid suppression that was no different from the average of the single-species treatment. This suggests that the relationship between predator diversity and prey suppression may be dependent on the presence of $C$. maculata beetles.

The fact that at low prey density a single beetle was just as effective at prey suppression as 2 or 4 beetles further supports the idea that $C$. maculata is contributing to an identity effect by dominating prey consumption in the diverse predator assemblage (Fig. 10A). When the aphid resource was limiting, intraspecific competition in the single species treatment limited prey suppression. However, when the prey resource was abundant, aphids were able to escape control, except at the highest beetle density (Fig. 10B). Taken together, these results suggest that the overall benefit of enhanced pest suppression in diverse predator guilds was due to an identity effect in which the $C$. maculata beetle was a key predator species that exhibited high rates of prey consumption. Thus, the observed benefit of diversity may merely be an artifact of the experimental design, with the likelihood that a given treatment composition includes C. maculata beetles increasing with diversity.

Lady beetles have long been highlighted as voracious predators with unique capacities for filling discrete spatial, temporal, and even prey-choice niches; traits which often allow these predators to yield additive or even super-additive effects when they occur simultaneously with other predator species (Snyder 2009). Several studies suggest 
that the presence of coccinellid beetles can be an important factor in influencing processes like natural pest suppression in species-rich systems due to the voracious consumption of prey by beetles and/or beetles foraging for prey at times or in locations that are complementary with other co-occurring predator species (Losey and Denno 1998b, Losey and Denno 1998a, Cardinale et al. 2003, Snyder et al. 2004, Straub and Snyder 2006). Therefore, given the ecology of this key group of predators, it seems likely that the presence of the pink-spotted lady beetle contributed to enhanced herbivore suppression in my diverse predator assemblages.

While these results implicate $C$. maculata as a dominant predator that is driving the positive effects of diversity on prey suppression, I do not rule out the possibility that other mechanisms may also be at work. Other predator species used in my experiments may be contributing to identity effects. For example, the damsel bug $N$. americoferis was effective at aphid suppression as well, but the impact of damsel bugs on aphids was not as consistent across species compositions as the impact of beetles. Additionally, complementarity or facilitation of prey capture may emerge when specific combinations of species are present, leading to an identity effect in which increasing diversity increases prey suppression by increasing the chances of including a particularly effective combination of species (Straub et al. 2008, Finke and Snyder 2010). Although these other factors may also contribute to the positive effect of predator diversity on aphid control, due to low replication of each unique predator composition, I did not have the power to investigate these relationships in detail.

I found that predator species identity was the key factor impacting the outcome of natural pest suppression in my experiments. Therefore, efforts to conserve total 
biodiversity are likely to enhance natural pest suppression because increasing the number of species in the community enhances the likelihood of capturing the benefits of a particular species with dominant traits (Huston 1997, Cardinale et al. 2006). However, from a management perspective, if the only benefit of diversity is to enhance the probability of conserving a single high-performing species, then the most efficient approach may be to directly target that particular species, rather than conserving biodiversity more broadly. In this case, I would suggest that targeted efforts to promote the abundance of the pink-spotted lady beetle $C$. maculata would be most effective at preventing outbreaks of bird cherry-oat aphids in cereal grains (Obrycki and Kring 1998, Bianchi and Werf 2004, Obrycki et al. 2009, Diepenbrock and Finke 2012). 


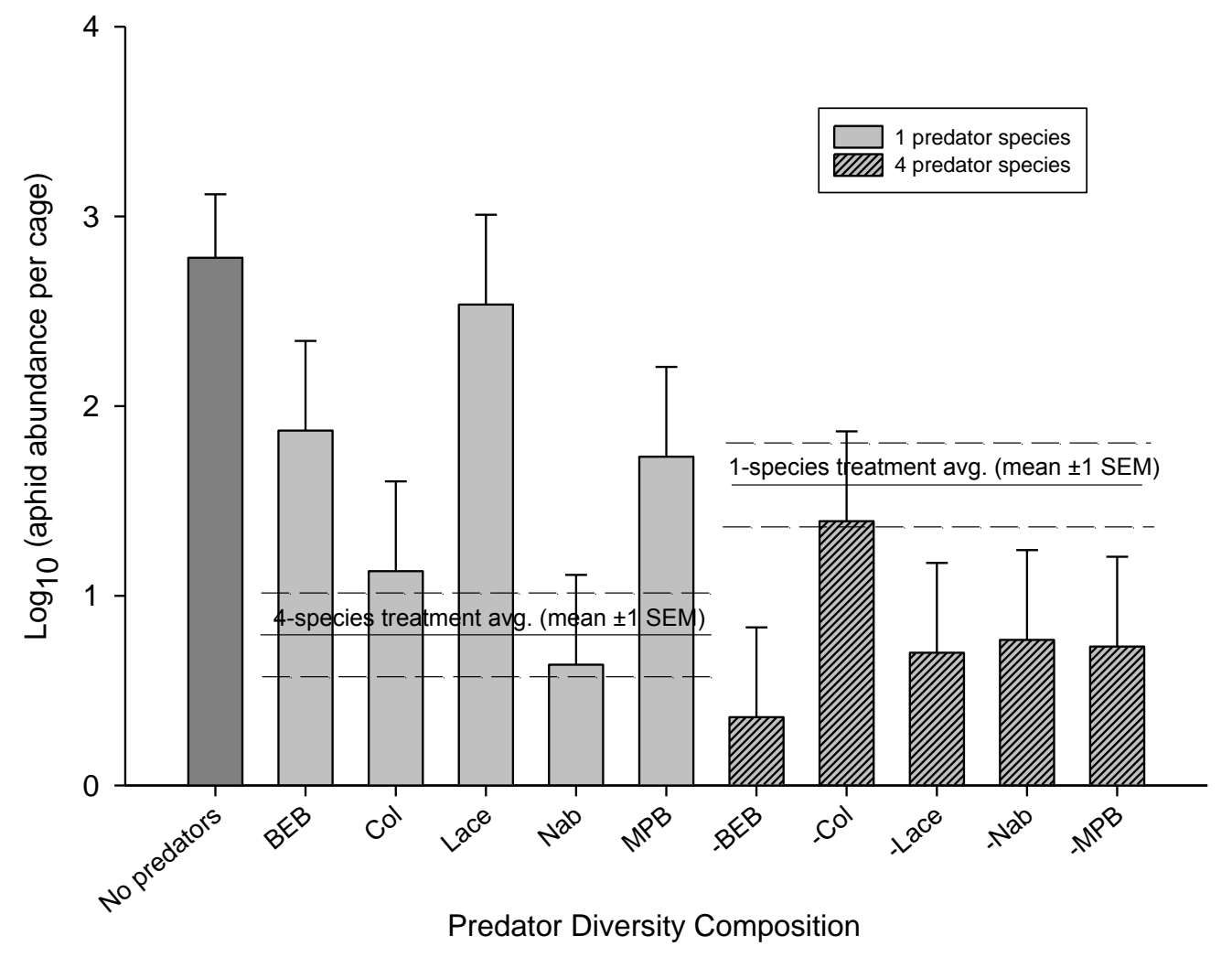

Figure 9. The effect of predator diversity (no-predator control, 1 predator species present, or 4 predator species present) and predator species composition on the total number of bird cherry-oat aphids (Rhopalosiphum padi) remaining in field cages after 4 weeks. The five unique species compositions comprising the 1-species treatment are compared to the average of the 4-species treatments, and the five unique species compositions comprising the 4-species treatment are compared to the average of the 1-species treatments. LSmeans \pm 1 SEM are shown. $X$-axis abbreviations represent predator species names with negative signs denoting the predator species that is missing from the 4-species composition. $\mathrm{BEB}=$ Geocoris punctipes, (big-eyed bug), Col= Coleomegilla maculata (pink-spotted lady beetle), $\mathrm{Lace}=$ Chrysoperla carnea (green lacewing larva), $\mathrm{Nab}=$ Nabis americoferis (damsel bug), and MPB=Orius insidiosus (minute pirate bug). 

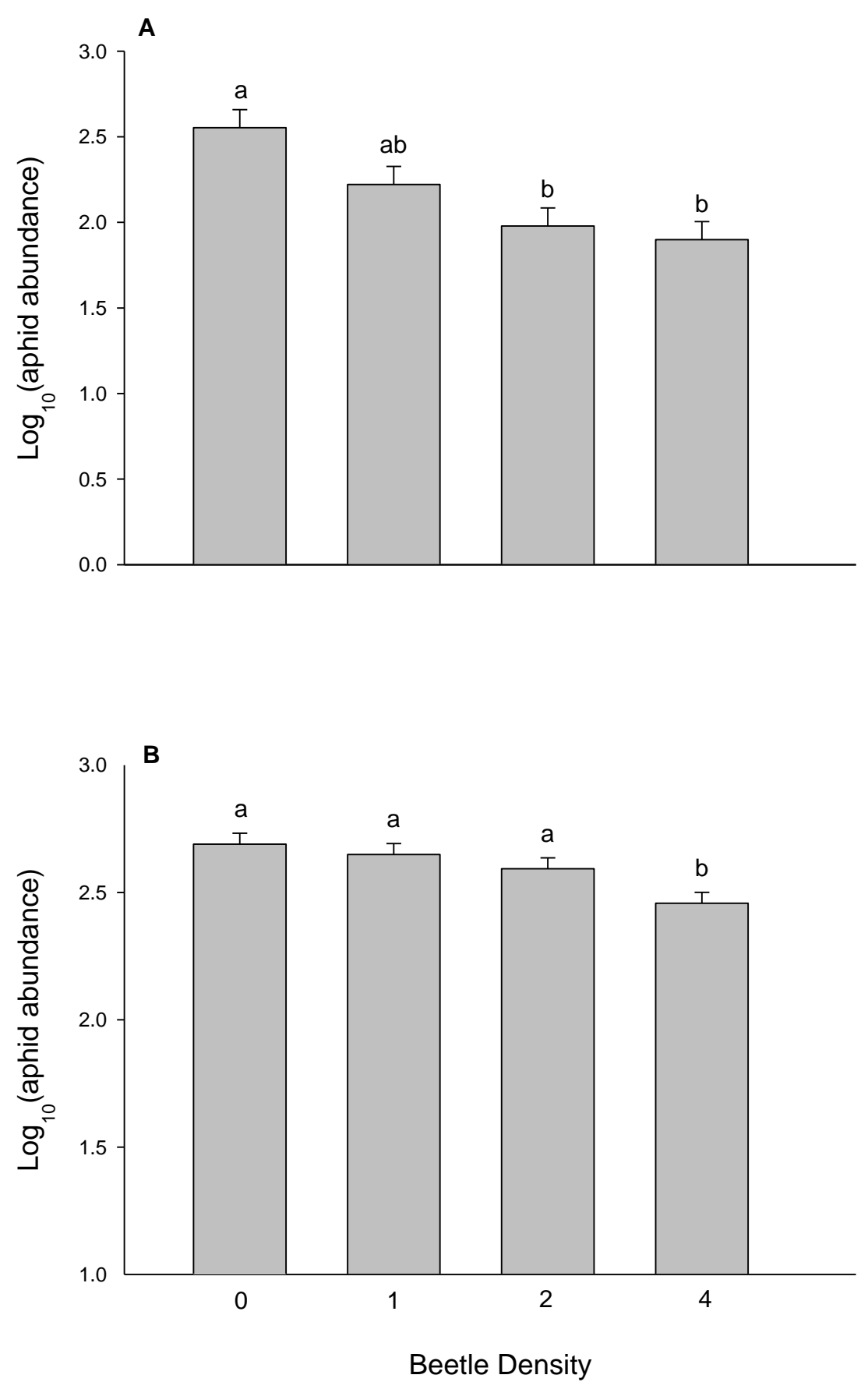

Figure 10. The impact of increasing Coleomegilla maculata beetle density on bird cherryoat aphid (Rhopalosiphum padi) abundance in wheat habitats at (A) low aphid density and (B) high aphid density. LSmeans \pm 1 SEM with different letters are significantly different at the $p<0.05$ level. Note that $\mathrm{Y}$-axis in panel B begins at 1.0. 


\title{
CHAPTER 4.
}

\section{CASCADING EFFECTS OF PREDATORS ON A VECTOR-BORNE PLANT PATHOGEN ARE NOT ALTERED BY PREDATOR DIVERSITY}

\begin{abstract}
While a growing number of studies have investigated the consequences of host biodiversity loss for disease occurrence, few have examined how declining predator diversity might indirectly influence the prevalence of vector-borne pathogens by directly impacting the vector organism. Here I examine whether predator diversity plays a role in the occurrence of an aphid-vectored plant pathogen, cereal yellow dwarf virus (CYDV), using the natural assemblage of predatory insects inhabiting wheat agroecosystems. I manipulated predator species richness in greenhouse mesocosms and measured the indirect effect of predators on the prevalence of CYDV in wheat plants. To further elucidate the mechanism(s) behind any observed response, I investigated whether altered predator diversity directly impacts vector abundance, the number of host plants occupied by vectors, or the feeding behavior of vectors. Overall, I found that increasing predator diversity had no impact on the prevalence of the CYDV pathogen in wheat habitats; however, the presence of a predator assemblage, regardless of species richness, did significantly reduce the proportion of plants infected. Vector suppression was greatest in the presence of diverse predator groups; however vector occupancy of wheat plants did not differ across levels of predator diversity. Therefore, reductions in pathogen prevalence were attributed to predator-induced changes in vector behavior such that when predators were present, vectors spent more time moving and less time feeding
\end{abstract}


on wheat plants. These results suggest that declines in predator species richness may not have immediate consequences for vector-borne pathogen outbreak; however, promoting predator communities in agroecosystems may have benefits for the management of insect-vectored pathogens.

\section{INTRODUCTION}

As human-mediated global change continues to threaten the persistence of species (Vitousek et al. 1997, Tilman et al. 2001), there is growing concern that the loss of biodiversity will increase the frequency of disease outbreaks (Daszak et al. 2000, LoGiudice et al. 2003). It has been hypothesized that conserving diversity, in particular host diversity, will diminish the occurrence of disease by 'diluting' disease risk (Ezenwa et al. 2006, Keesing et al. 2006, Borer et al. 2009, Keesing et al. 2010); however, recent reviews suggest that the relationship between diversity and disease risk may be much more complex than originally predicted (Wood and Lafferty 2012, Salkeld et al. 2013). Studies find that the response of disease to diversity loss may be positive, negative, or neutral depending on the ecological dynamics of specific disease systems and the spatial scale of investigation (Wood and Lafferty 2012, Salkeld et al. 2013). Ultimately, understanding the consequences of biodiversity loss for disease dynamics will require a community-level perspective. Traditionally, studies of disease risk focused predominantly on the interactions that occur between hosts and pathogens. In reality, pathogen transmission involves many species across multiple trophic levels, including not only hosts and pathogens, but their competitors, mutualists, predators, and in the case of vector-borne pathogens, their vectors as well. It is only by incorporating this greater 
level of complexity that we might begin to predict how disease risk will respond to diversity loss across variable environments (Dobson 2004, Power and Mitchell 2004, Keesing et al. 2006, Johnson and Thieltges 2010, Keesing et al. 2010, Roche et al. 2012, Wood and Lafferty 2012, Salkeld et al. 2013).

A community-level perspective leads to a greater emphasis on the role of higher trophic levels, particularly predators, in determining disease risk. Predators have traditionally been incorporated into studies of disease dynamics as consumers of hosts (Ostfeld and Holt 2004, Holt and Roy 2007, Borer et al. 2009, Duffy et al. 2011). However, in systems where pathogens are dependent on a vector for transmission from host to host, predators can also affect disease risk indirectly via direct effects on vectors (Weber et al. 1996, Landis and Van der Werf 1997, Smyrnioudis et al. 2001, Hodge and Powell 2008, Moore et al. 2009). Studies have found that predators can influence vectorborne disease risk via a variety of mechanisms, including impacts on vector abundance, feeding behavior, and/or movement, each with potentially unique consequences for disease risk (Moore et al. 2009, Finke 2012). For example, by decreasing the abundance of vectors available to transmit pathogens from host to host or by reducing the duration of time that individual vectors spend feeding on host plants, predators can indirectly reduce the occurrence of disease in host populations (Landis and Van der Werf 1997, Smyrnioudis et al. 2001, Hodge and Powell 2008). On the other hand, predators may contribute to a higher risk of disease if they stimulate vectors to move more frequently from host to host in response to their perceived risk of predation (Hodge and Powell 2008, Hodge et al. 2010). In reality, it will likely be a combination of these predator 
impacts and the relative strengths of each that determine how predators influence pathogen prevalence.

While there is mounting evidence that individual predator species can have cascading indirect effects on disease risk via direct effects on vectors, what remains relatively unexplored is the role that predator diversity might play in these interactions (Keesing et al. 2006, Carlson et al. 2009). Although little is known about the relationship between predator diversity and vector-borne disease risk, insight can be gained from studies exploring the consequences of predator diversity loss in the context of herbivore suppression and trophic cascades. It has been well-documented that predator species richness and evenness influence the cascading effects of predators on plant biomass through changes in prey abundance and behavior (Schmitz and Suttle 2001, Cardinale et al. 2003, Finke and Denno 2004, Schmitz et al. 2004, Bruno and O'Connor 2005, Byrnes et al. 2005, Preisser et al. 2005, Griffin and Thaler 2006, Prasad and Snyder 2006, Steffan and Snyder 2010). However, the relationship can vary depending on the particular system investigated and the functional traits of predators and prey involved (Bruno and Cardinale 2008, Straub and Snyder 2008, Letourneau et al. 2009, Crowder et al. 2010, Finke and Snyder 2010, Steffan and Snyder 2010, Tylianakis and Romo 2010). Likewise, the effects of predators on pathogen prevalence may also vary as a function of predator diversity. Although studies explicitly investigating predator diversity are lacking, previous studies demonstrate that the impacts of predators on pathogen prevalence can differ based on the identity of the natural enemy species present. For example, the parasitoid wasp Aphidius rhopalosiphi was found to reduce the prevalence of barley yellow dwarf virus in wheat, while in the same study the predatory lady beetle Coccinella septempunctata increased 
prevalence (Smyrnioudis et al. 2001). Likewise, larvae of the predatory syrphid Sphaerophoria rueppellii decreased transmission rates of broad bean wilt virus by aphids, but transmission rates were unaffected by the lady beetle Adalia bipunctata (Belliure et al. 2011). These results suggest that predator identity matters for pathogen prevalence and suggests that diversity may be important, but we still do not know whether the combined effects of these natural enemies will be additive or not.

Currently, studies examining the consequences of predator diversity loss for vector-borne pathogens and disease risk are limiting; although the role of biodiversity loss, particularly at the level of host organisms, has been investigated (LoGiudice et al. 2003, Power and Mitchell 2004, Kilpatrick et al. 2006, Johnson et al. 2008). Here I aim to bridge the gap in the diversity and vector-borne pathogen literature by experimentally manipulating predator species richness, and measuring both the direct and indirect effects of altered predator diversity on pathogen vectors and pathogen prevalence respectively. By doing so, I demonstrate that predators can reduce the prevalence of a vector-borne plant pathogen by stimulating vector movement and reducing the time that vectors spend feeding, but this impact is not influenced by changes in predator species richness.

\section{MATERIALS \& METHODS}

Study system

Wheat (Triticum aestivum L.) is one of many economically important species of cereal grains that is susceptible to the persistently-vectored barley and cereal yellow dwarf viruses (B/CYDVs) (Plumb and Thresh 1983). The B/CYDVs are a complex of RNA viruses that are transmitted exclusively by aphids via feeding as they move from 
plant to plant. Once infected, plants can exhibit a variety of disease symptoms including stunting, yellowing or purpling of marginal leaf tissues, reduced seed set, and even death (Irwin and Thresh 1990, D'Arcy and Burnett 1995). The efficiency of pathogen transmission within the B/CYDV complex varies with aphid species and virus strain (Rochow 1970, Gray and Gildow 2003); in general however, aphid species that are capable of vectoring these viruses require relatively longer periods of feeding on hosts to successfully complete the transmission process (Gray and Gildow 2003). While there are multiple virus strains within the B/CYDV complex, I used the CYDV-RPV strain in the family Poleroviridae.

Within the diverse community of arthropods that inhabit wheat systems, I focused on one species of herbivorous insect, the bird cherry-oat aphid Rhopalosiphum padi, a phloem-feeding generalist of cereal grains. Bird cherry-oat aphids are known to vector the CYDV-RPV strain with high efficiency (Gray et al. 1991, Gray and Gildow 2003), and are thus considered important pests of wheat. These aphids are attacked by a diverse guild of natural enemies that have the potential to suppress cereal aphid populations in grain crops (Kring et al. 1985, Rice and Wilde 1988, Brewer and Elliott 2004, Schmidt et al. 2004), including larvae of the green lacewing Chrysoperla carnea (Stephens) (Neuroptera: Chrysopidae), the pink-spotted lady beetle Coleomegilla maculata (DeGeer) (Coleoptera: Coccinellidae), the damsel bug Nabis americoferus (Carayon) (Hemiptera: Nabidae), the minute pirate bug Orius insidiosus (Say) (Hemiptera: Anthocoridae), and the big-eyed bug Geocoris punctipes (Say) (Hemiptera: Geocoridae). 


\section{Indirect effects of predator species richness on pathogen prevalence}

To assess the impact of predator diversity on pathogen prevalence as mediated by predator impacts on vectors, I exposed $R$. padi aphids to predator communities that varied in species richness and measured (1) the indirect effects of predator diversity on pathogen prevalence and (2) the direct effects of predator diversity on the abundance and location of vectors within wheat habitats. Experimental units were $60 \mathrm{~cm} \times 60 \mathrm{~cm} \times 60 \mathrm{~cm}$ bug dorm insect cages (MegaView Science Co., Ltd., Taichung, Taiwan) maintained in the University of Missouri Ashland Road greenhouse facility (16:8 L:D, variable temp: 26 ${ }^{\circ} \mathrm{C}-38^{\circ} \mathrm{C}$ ). Each cage contained a single tray of 10 -day old soft red winter wheat plants arranged in a $6 \times 10$ grid for a total of 60 wheat plants per cage (similar to Fig.1). Prior to use in the experiment, all aphids were given the opportunity to acquire the pathogen by feeding on confirmed CYDV-RPV-infected plant tissue placed in petri dishes in the dark for 48 hours without disturbance. I and others have utilized this aphid acquisition protocol with great success for the inoculation and creation of virus-infected plants maintained in greenhouse colonies (E. Y. Long, personal observation and C. E. Mitchell, personal communication). After the 48-hr virus acquisition period, clippings of infected plant tissue containing 200 viruliferous $R$. padi aphids were placed among the two most distal rows of wheat in each cage (those farthest from the cage opening) and allowed 24 hours to settle before the addition of predators.

Predator communities were assembled using five generalist predatory insect species that occurred commonly based on visual counts made in wheat fields: green lacewing larvae (C. carnea), pink-spotted lady beetle adults (C. maculata), damsel bug adults (N. americoferus), minute pirate bug adults (O. insidiosus), and big-eyed bug 
adults (G. punctipes). All predatory insects were collected in the field by hand and with a D-vac suction sampler (Rincon-Vitova Insectaries, Ventura, CA), with the exception of the $C$. carnea larvae, which were obtained commercially from Rincon-Vitova Insectaries (Ventura, CA). Predator diversity treatments were created from the pool of 5 predator species according to three treatments: Control (no predators added), 1 predator species added, or 4 predator species added (Fig. 4). The 1-predator and 4-predator species treatments each included 10 replicates (two replicates of each of the five unique species compositions possible from the pool of 5 predator taxa) and the No-predator control treatment included 6 replicates, for a total of 26 experimental units. I employed a substitutive design such that total predator density across treatments containing predators was held constant at 4 individuals per cage.

After 48 hours, I counted the number of aphids remaining on each of the 60 individual host plants in the habitat to determine the direct effect of predators on (1) total aphid abundance, and (2) the rate of occupancy of hosts with aphids (i.e. the number of host plants with at least one aphid present). Following aphid counts, all wheat plants were sprayed with the systemic aphicide pymetrozine (Endeavor, Syngenta, Greensboro, NC) to exterminate aphids and thus cease virus transmission. To allow virus titer to accumulate in infected plants, wheat plants were given an additional 4 weeks to grow without disturbance within experimental cages. After this time, wheat plants were harvested and stored at $-80^{\circ} \mathrm{C}$ until infection status could be determined by extracting total RNA (RNeasy Plant Mini Kit, Qiagen Group, Germantown, MD), and using reverse-transcription polymerase chain reaction (RT-PCR) to detect virus presence in individual plants. A total of 16 plants, evenly distributed across the habitat, were sampled 
from each cage, and pathogen prevalence was calculated as the proportion of the 16 plants from each cage that tested positive for CYDV-RPV (Fig. 11).

To determine the indirect effect of predator diversity (Control vs. 1-species vs. 4species) on pathogen prevalence, the proportion of plants infected with CYDV-RPV were compared across treatments using analysis of variance (Proc Mixed, SAS version 9.2, SAS institute, Cary, NC). To investigate the potential mechanisms by which predators might influence pathogen prevalence, the direct effects of predator diversity (Control vs. 1-species vs. 4-species) on (1) total aphid abundance and (2) the number of host plants occupied by at least one aphid were compared across treatments in two separate analyses of variance (Proc Mixed, SAS version 9.2, SAS institute, Cary, NC). Finally, I conducted regression analysis to further investigate whether pathogen prevalence is influenced by changes in vector abundance with predator diversity treatment as a covariate (Proc Reg, SAS version 9.2, SAS institute, Cary, NC).

\section{Behavioral response of vectors to predator species richness}

To determine whether the indirect effects of predator diversity on pathogen prevalence are due to the direct effects of predator diversity on the feeding behavior of pathogen vectors, I conducted an observational study in the laboratory. The goal of this experiment was to observe changes in vector movement in response to predator diversity treatments and to relate that movement to potential changes in vector feeding behavior.

Experimental units were 10-gallon glass terraria (Aqua Culture, Wal-Mart Stores Inc., Bentonville, AR), each containing 5 T. aestivum wheat plants planted directly into soil at the bottom of the cage and arranged in a row (Fig. 12). The first wheat plant in 
each row (plant 1) was roughly 5 weeks old and previously inoculated with CYDV-RPV, while the remaining 4 wheat plants (plants 2-5) were 10-day old virus-free wheat plants. Thirty virus-free $R$. padi aphids were released onto the infected plant 1 in each cage and allowed 1 hour to acquire the virus before the addition of predators.

The same generalist predatory insect species were used in this experiment as in the previous experiment with the exception of $G$. punctipes, which was not available in the field at the time of this study. Predator communities were assembled from the pool of 4 predator species according to three treatments: Control (no predators added), 1 predator species added, or 3 predator species added. The 1-species and 3-species treatments each included 12 replicates ( 3 replicates of each of the 4 unique species compositions) and the no-predator Control treatment included 6 replicates, for a total of 30 experimental units. I employed a substitutive design such that total predator density across treatments containing predators was held constant at 3 individuals per cage.

Visual observations were made every 6 hours over a 48 hour period for a total of 9 observations. At each observational period, I made note of the location of each individual aphid and predator, i.e. whether they were located on plants $1-5$, on the soil, or on the cage. I estimated aphid movement in response to predator treatment as the average number of plants moved per aphid per 6 hour observational period. Because I was interested in determining how vectors responded behaviorally to the presence of a predation threat, but did not want this effect confounded with overall differences in aphid abundance across predator treatments, I attempted to control for differences in aphid abundance across treatments by adding aphids where aphid density was less than 30 individuals after 24 hours (sensu Steffan and Snyder 2010). 
The impacts of predator diversity (Control vs. 1-species vs. 3-species) on 1) aphid movement (i.e. average number of plants moved per aphid per 6 hour period) and 2) the number of plants occupied with at least one aphid were determined by repeated measures analyses of variance (Proc Mixed, SAS version 9.2, SAS institute, Cary, NC). Covariance structures were constructed for each mixed model repeated measures analysis and the best-fit model was determined using Bayesian Information Criterion. For aphid movement, a compound symmetry covariance structure was determined to be the best-fit model, whereas an unstructured covariance structure was the best-fit for the number of plants occupied with aphids.

\section{RESULTS}

\section{Indirect effects of predator species richness on pathogen prevalence}

I found a significant overall effect of predator treatment on the prevalence of cereal yellow dwarf virus in wheat (Fig. $\left.13 \mathrm{~A}, F_{2,17}=7.00, p=0.006\right)$. This significant effect arose because the proportion of plants infected with CYDV-RPV was reduced when predators were present as compared to when predators were absent (Fig. 13A, 1species vs. control: $t=3.49, p=0.003 ; 4$-species vs. control: $t=3.01, p=0.008)$. However, when predators were present, their impact was consistent across levels of predator diversity, with no difference in the proportion of plants infected with CYDV-RPV when 1 predator species or 4 predator species were present (Fig. 13A, 1-species vs. 4-species: $t=0.73, p=0.48)$. Therefore, while predators indirectly influenced the occurrence of CYDV-RPV in wheat, with pathogen prevalence roughly 3-times lower when predators were present, there was no additional benefit of increasing predator species richness. 
When exploring possible mechanisms by which predators may indirectly impact pathogen prevalence, I found a significant effect of predator treatment on vector abundance (Fig. 13B, $F_{2,17}=3.39, p=0.057$ ); however, the magnitude of predator effects on vector abundance were not consistent with the magnitude of predator effects on pathogen prevalence. Whereas predator species richness did not impact pathogen prevalence, increasing predator species richness did strengthen vector suppression. In fact, only the 4-species predator assemblages significantly reduced aphid abundance as compared to the no-predator control (Fig. $13 \mathrm{~B}, t=2.56, p=0.021$ ). Vector abundance in the presence of the 1-species predator assemblages did not differ from the control (Fig. 12B, $t=0.98, p=0.34)$. Furthermore, when I examined the effect of vector abundance on pathogen prevalence by regression analysis with predator treatment as a covariate, I found no evidence of a relationship (Fig. 14, $Y=6 \mathrm{e}^{-4} x+0.1494, r^{2}=0.03, p=0.78$,). Therefore, it does not appear that predator effects on vector abundance are responsible for the suppressive effects of predators on pathogen prevalence.

There was also no evidence to support the idea that predators influenced pathogen prevalence by altering host plant occupancy by vectors. There was no effect of predator treatment on the number of wheat plants occupied by at least one aphid, rather the number of plants occupied by vectors was the same whether no predators, 1 species, or 3 species were present (Fig. 13C, $F_{2,23}=1.22, p=0.31$ ).

\section{Behavioral response of vectors to predator species richness}

I did find evidence that the suppression of pathogen prevalence by predators may be the result of predator impacts on vector behavior. Predator treatment significantly influenced vector movement (Fig. 15, $F_{2,27}=4.14, p=0.027$ ). And like the effects of 
predators on pathogen prevalence, this significant effect arose because vectors moved greater distances when predators were present as compared to when predators were absent (Fig. 15, control vs. 1 -species: $t=2.83, p=0.009$; control vs. 3 -species: $t=2.27$, $p=0.031$ ). However, vector movement was not influenced by the species richness of the predator assemblage, with the magnitude of the predator effect being the same whether 1 or 3 predators species were present (Fig. 15, $t=0.69, p=0.50$ ). Although the number of plants moved by aphids varied depending on the observational period $\left(F_{8,216}=6.36\right.$, $p<0.0001$ ), the effect of predator treatment across observational periods was always consistent $\left(F_{16,216}=1.46, p=0.12\right)$.

Despite the fact that aphids moved greater distances in the presence of predators, I again found no evidence that predators or predator diversity influenced the number of plants occupied by at least one vector. Although the number of plants occupied increased over time $\left(F_{8,27}=6.96, p<0.0001\right)$, occupancy rates did not vary across predator treatments overall or across time (predator treatment: $F_{2,27}=0.41, p=0.67$; predator treatment $\mathrm{x}$ observational period: $\left.F_{16,27}=0.51, p=0.92\right)$.

\section{DISCUSSION}

Working within the CYDV plant pathogen system, I found evidence for a key role of predators, but not predator diversity, in indirectly influencing the prevalence of a vector-borne plant pathogen. In my experiments, the proportion of plants infected with aphid-vectored CYDV was significantly reduced when predators were present, but was not further influenced by altered levels of species richness in the predator community (Fig. 13A). In contrast, predator diversity did have a significant impact on vector 
abundance, such that vector population suppression only occurred in the presence of diverse predator assemblages (Fig. 13B). Furthermore, vector abundance was not related to pathogen prevalence (Fig. 14), and this was likely the case because the number of plants occupied by at least one aphid did not vary across treatments (Fig. 13C), even though the overall number of aphids in the habitat did vary across treatments. Therefore, because only one vector is required to transmit the pathogen from plant to plant, overall reductions in vector abundance did not impact pathogen prevalence.

When I examined predator diversity effects on vector behavior within this system, I observed a pattern similar to that of pathogen prevalence: the presence of predators had a significant impact on vector movement, but predator diversity had no impact (Fig. 15).

When predators were present, pathogen vectors moved more from plant to plant, suggesting that they spent more time 'in motion' as compared to when predators were absent. I used vector movement as a proxy for vector feeding behavior because in theory, if vectors are moving more/greater distances, they consequently have less time to settle and feed on hosts. Reductions in time spent feeding can be particularly important for the transmission of persistent pathogens, which require vectors to engage in relatively longer feeding sessions so that pathogen particles can be acquired by hindgut epithelia and then circulated to the accessory salivary glands where they can be inoculated into a host (Gray and Gildow 2003). Given that all R. padi aphids were given the same period of time to acquire the pathogen before the onset of experiments, it was likely that predators impacted pathogen prevalence by altering the time that aphids had to inoculate the pathogen. The amount of time that vectors have to inoculate a pathogen into hosts has been shown to influence the efficiency of CYDV-RPV transmission by $R$. padi aphids, 
such that transmission efficiency increases rapidly from $33 \%$ given a 30 -minute feeding period to $>50 \%$ given a 2 -hour feeding period (Power et al. 1991). The direct impact of predators on vector behavior could explain the pattern of reduced pathogen prevalence I observed in plants. Because vectors were unable to settle and feed for extended periods of time in the presence of predators, due to either the perceived threat of predation or direct predator harassment, the efficiency of pathogen transmission and the proportion of plants infected with CYDV-RPV were reduced.

The relative impact of predators on pathogen prevalence will likely vary depending on the intricacies of the pathogen system. For example, my results may have differed substantially if my focal pathogen was transmitted in a non-persistent, rather than persistent, manner from host to host. In contrast to persistent pathogens, nonpersistent pathogens are less-intimately associated with the vector so that interactions between vector tissues and pathogen particles are limited to vector mouthparts, with acquisition occurring along the surface of feeding structures that come into direct contact with infected host tissues (Gildow 1987). As a result, pathogen particles can quickly be lost from vector mouthparts as they feed on consecutive hosts, resulting in a decrease in transmission efficiency with an increase time spent feeding (Gildow 1987, Nault 1997, Gray and Banerjee 1999). Therefore, we might predict that by reducing vector feeding time and stimulating vector movement, predators may increase the prevalence of a nonpersistently transmitted pathogen in a host population. And in fact, it has been documented that predators/parasitoids can increase the prevalence of non-persistent plant pathogens by stimulating both the movement and probing behavior of pathogen vectors (Hodge et al. 2010). 
These results support recent reviews that challenge the notion that greater species richness will always dilute disease risk (Wood and Lafferty 2012, Salkeld et al. 2013). I found that diversity had no impact on disease risk, and indeed it seems likely that the relationship between predator diversity and disease risk in nature will be idiosyncratic, because pathogen prevalence is influenced by the traits and behaviors of predators and prey, as well as the intricacies of the pathogen system (e.g. mode of transmission). Based on these results, it does not seem likely that declines in predator diversity will necessarily lead to immediate increases in the prevalence of persistently-vectored plant pathogens; however, if at some point predators become locally extinct there will likely be consequences for the occurrence of persistently-vectored pathogens.

Furthermore, these results could have important implications for the maintenance of predator diversity in ecosystems that are susceptible to herbivore and/or pathogen outbreaks. I show that maintaining species richness in the predator community can be beneficial for the biological control of herbivore pests acting as pathogen vectors, a result that is consistent with findings that the presence of a diverse guild of predators can strengthen herbivore suppression in a variety of ecosystems (Prasad and Snyder 2006, Snyder et al. 2006, Straub and Snyder 2008, Finke and Snyder 2010, Tylianakis and Romo 2010). So maintaining a diverse predator community may be beneficial for the suppression of herbivores acting as pathogen vectors; however, promoting predators in general, at low or high diversity, may provide the added bonus of contributing positively to the management of persistently-transmitted plant pathogens in agroecosystems via altering vector behavior. 
I conclude from this study that it was the presence of predators, not necessarily predator diversity, which initiated a behavioral cascade whereby vectors spent less time feeding and more time moving from one host to another, leading to reductions in pathogen prevalence via reducing pathogen transmission efficiency. Predators have been shown to play a variety of critical roles in ecosystems and it has been argued that efforts to maintain predator species richness is a worthwhile effort, as these organisms are predicted to be at greater risk of extinction. My studies support the notion that predators do indeed play important roles and their absence from 'ecological webs' could have important consequences for the outcome of multi-species interactions like pathogen transmission, and the progression of disease in ecological communities. 


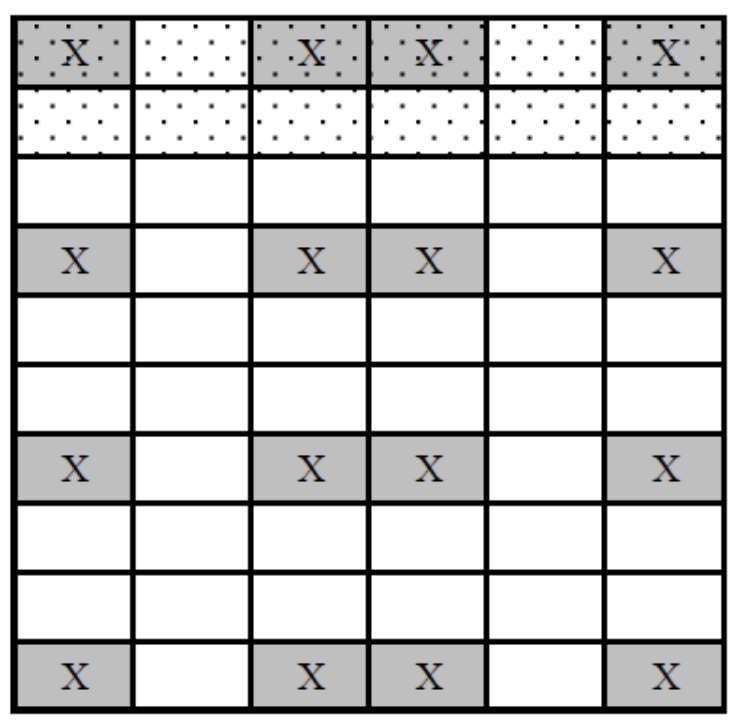

Aphids released in these

two rows

Figure 11. Arrangement of wheat habitat with each box representing a single wheat plant. Two-hundred viruliferous bird cherry-oat aphids (Rhopalosiphum padi) were haphazardly released onto the two most distal rows of plants (denoted by dots). Pathogen prevalence was calculated as the proportion of 16 sub-sampled wheat plants (gray boxes with an "X") that tested positive for CYDV-RPV. 


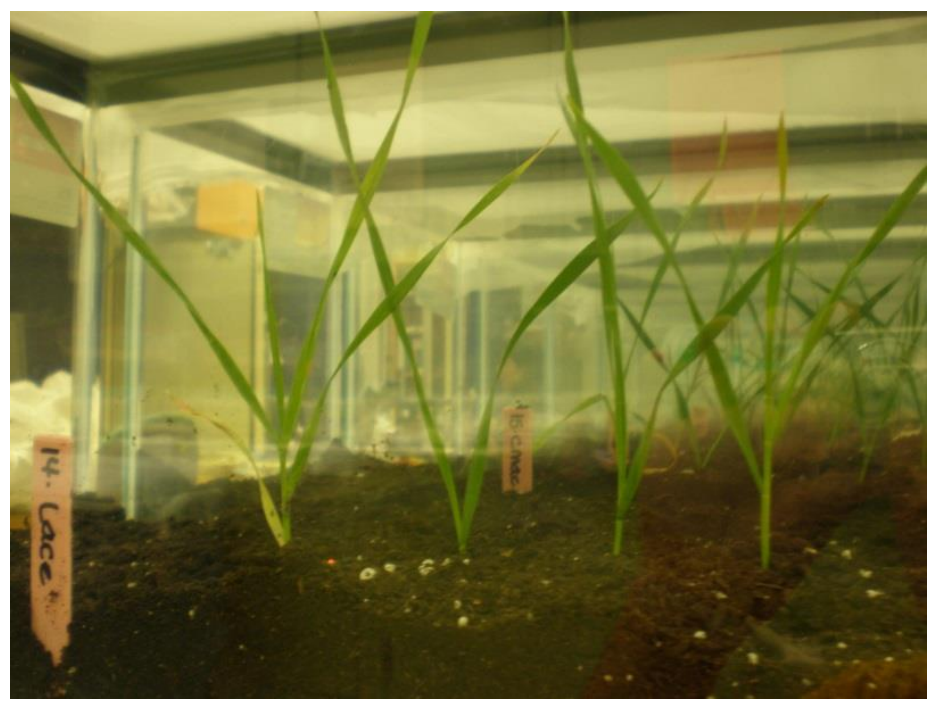

Figure 12. Arrangement of 5 wheat plants in 10-gallon terraria to conduct visual observations of bird cherry-oat aphid (Rhopalosiphum padi) movement in response to predators. 

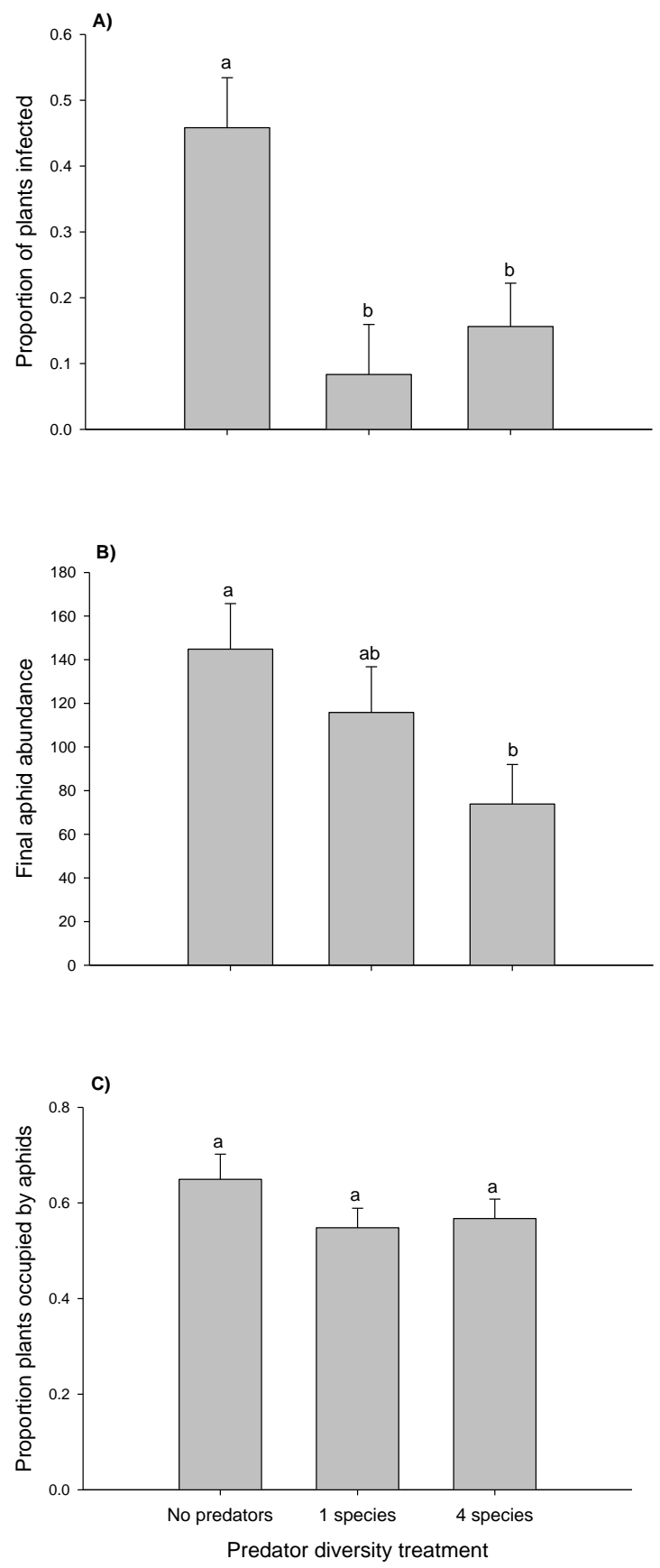

Figure 13. The effect of predator species richness (no predators, 1 species or 4 species present) on (A) pathogen prevalence (the proportion of wheat plants infected with CYDV-RPV out of a sub-sample of 16 plants), (B) the abundance of bird cherry-oat aphids (Rhopalosiphum padi), vectors of CYDV-RPV, and (C) the proportion of wheat plants (out of 60) occupied by at least one $R$. padi aphid after a 48 -hr interaction period in greenhouse mesocosms. LSmeans \pm 1 SEM with different letters are significantly different at the $p<0.05$ level. 


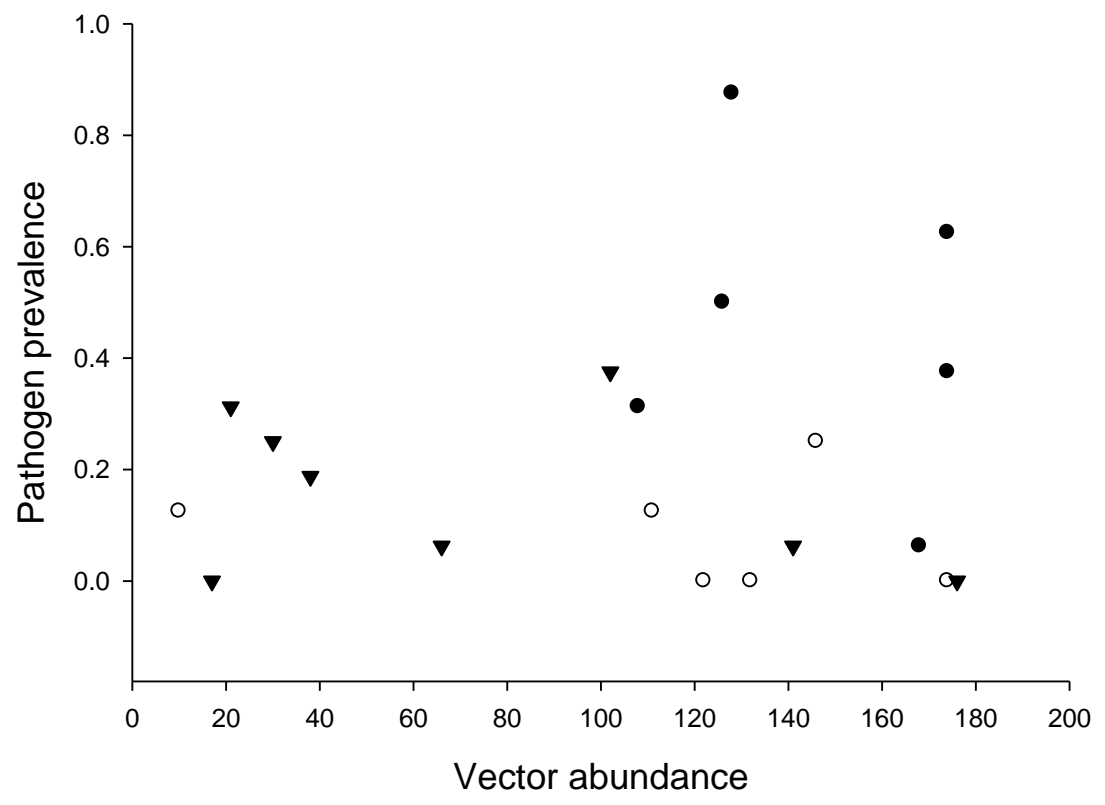

Figure 14. The relationship between vector (bird cherry-oat aphid Rhopalosiphum padi) abundance and pathogen prevalence (the proportion of wheat plants infected with CYDV-RPV) with predator diversity treatment used as a covariate: $\bullet=$ nopredator control, $\mathrm{o}=1$ predator species present, and $\boldsymbol{\nabla}=4$ predator species present. There was no relationship between vector abundance and pathogen prevalence $\left(Y=6 \mathrm{e}^{-4} x+0.1494, r^{2}=0.03, p=0.78\right)$. 


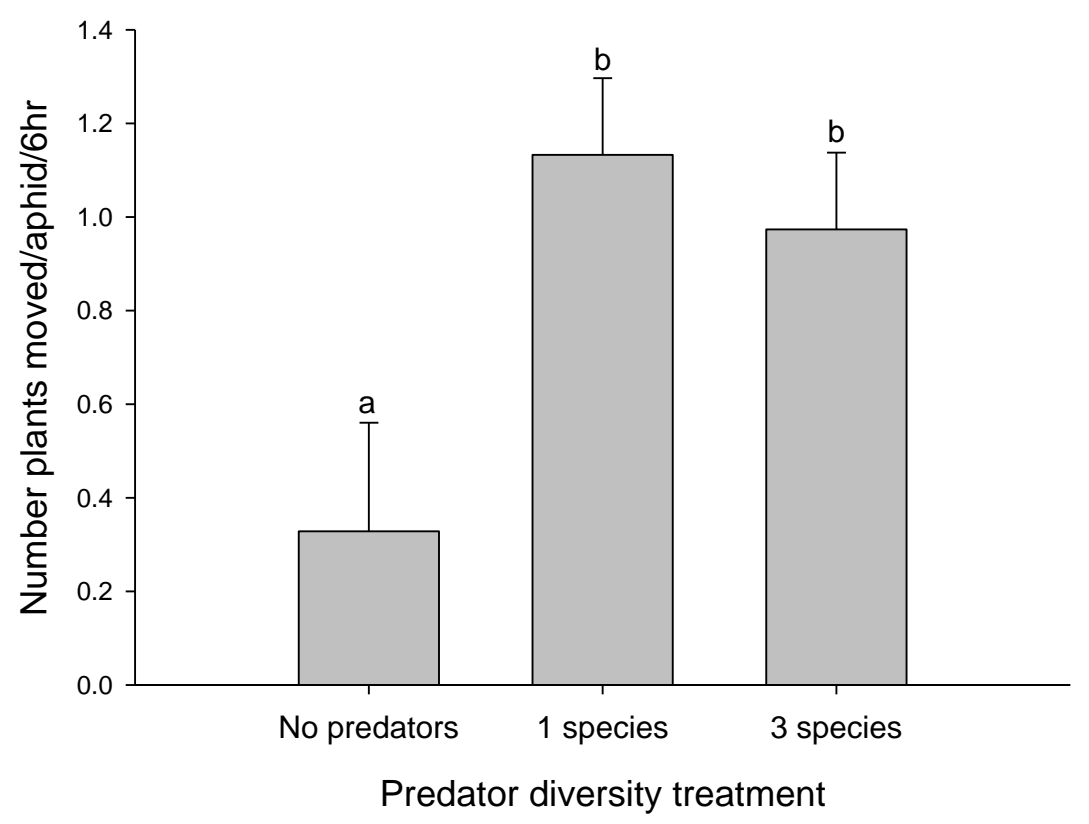

Figure 15. The effect of predator species richness (no predators, 1 species or 3 species present) on the average number of plants moved by bird cherry-oat aphids (Rhopalosiphum padi) per 6-hr observational period. Nine visual observations were made over a 48 -hr period. LSmeans \pm 1 SEM with different letters are significantly different at the $p<0.05$ level. 


\section{CHAPTER 5.}

\section{THE IMPACT OF ACQUISITION ACCESS PERIOD ON THE EFFICIENCY OF CEREAL YELLOW DWARF VIRUS TRANSMISSION BY THE APHID VECTOR RHOPALOSIPHUM PADI (HEMIPTERA: APHIDIDAE)}

\section{INTRODUCTION}

Perhaps some of the most damaging plant pathogens are those that are transmitted by arthropods, quite often insects (Agrios 2005). These vector-borne pathogens, can give rise to economically important diseases in cultivated crops worldwide (Agrios 2005). The management of insect-vectored pathogens can be particularly challenging because minimizing disease outbreak involves managing not only the pathogen source (infected hosts serving as pathogen reservoirs), but also populations of pathogen vectors. Vector species identity can vary widely depending on the focal pathogen, and it is often the case that more than one vector species is capable of transmitting the same pathogen (Gray and Banerjee 1999). Furthermore, pathogen vectors can vary in their physiological and behavioral traits, which may pose additional challenges to effective vector, and therefore disease management.

One particularly important factor in influencing vector-borne pathogen prevalence is the window of time available for vectors to feed on hosts. Time spent feeding is important because it can impact the efficiency with which a vector transmits pathogens from one individual to another (Gray and Banerjee 1999). Pathogen transmission is a two-step process that occurs successfully only when a vector (1) feeds upon an infected 
host and acquires the pathogen, and (2) subsequently feeds upon a novel host and inoculates the pathogen. As pathogen transmission is dependent upon these two key steps, it follows that any factor that influences vector feeding time can further impact transmission efficiency and ultimately pathogen prevalence in a host population.

Some of the best-studied vector-borne plant pathogens are the aphid-vectored barley and cereal yellow dwarf viruses (Irwin and Thresh 1990, D'Arcy and Burnett 1995). This suite of viruses is composed of four strains of Luteoviruses (BYDV-PAV, MAV, SGV, and SMV), and a single Polerovirus (CYDV-RPV) (Gray and Gildow 2003). Managing outbreaks of these pathogens can be difficult because these viruses are vectored by more than 20 aphid species (Irwin and Thresh 1990, D'Arcy and Burnett 1995). Furthermore, pathogen transmission efficiency varies widely with both host plant and aphid species (Rochow 1970, Gray and Gildow 2003). The time required by aphids to feed on infected plants to obtain virions, the acquisition access period (AAP), as well as the time required by viruliferous aphids to feed on healthy plants to transfer virions, the inoculation access period (IAP), are known to influence the success of pathogen transmission (Gray et al. 1991, Power et al. 1991, Gray and Gildow 2003).

The AAP and IAP have been manipulated within this suite of viruses to evaluate how pathogen transmission efficiency varies in conjunction with aphid species and specific virus strains (Gray et al. 1991, Power et al. 1991). These studies have shown that both AAP and IAP can influence the efficiency of pathogen transmission, and furthermore that transmission efficiency can vary with aphid species. For example, the CYDV-RPV and BYDV-PAV isolates were acquired by Rhopalosiphum padi aphids from infected oats in as little as 15 minutes; however the acquisition access periods 
required for $50 \%$ of aphids to transmit each virus strain were 2-3 hours, or 1-2 hours respectively for each virus isolate. In contrast, a different vector species, Sitobion avenae required a 30-minute acquisition access period to acquire BYDV-PAV from infected oats, with $50 \%$ of aphids successfully transmitting the PAV isolate after a 10-12 hour acquisition access period. When examining the impact of inoculation access period (IAP), it was found that $R$. padi aphids were capable of inoculating oats with either CYDV-RPV or BYDV-PAV after a 30-minute IAP; however transmission efficiencies varied such that $33 \%$ or $24.6 \%$ of $R$. padi aphids transmitted the RPV and PAV isolates respectively given a 30-minute IAP. While these studies have manipulated the acquisition and inoculation access periods for a combination of vector, host, and virus isolates, there remain innumerable combinations of host/vector/viral strains for which the AAP/IAP and transmission efficiencies have yet to be described.

Given that transmission efficiency can vary specifically with plant and vector species, as well as with pathogen strain and duration of vector feeding, I set out to examine the impact of AAP on the efficiency of CYDV-RPV transmission by the bird cherry-oat aphid (Rhopalosiphum padi) in wheat (Triticum aestivum). By manipulating the time available to vectors to access virus-infected plant tissues, I attempted to evaluate the relative importance of the first step of the pathogen transmission process, pathogen acquisition, on the overall efficiency of pathogen transmission. 


\section{MATERIALS \& METHODS}

\section{Impact of acquisition time on $R$. padi transmission efficiency of CYDV-RPV}

I set up an experiment to evaluate how altering vector acquisition access period would influence the efficiency with which $R$. padi aphids transmitted the CYDV-RPV pathogen to soft red winter wheat plants. This experiment was conducted at the University of Missouri Ashland Road greenhouse facility (16:8 L:D, 22-23ํ). To manipulate vector acquisition access period, groups of 15-20 virus-free $R$. padi aphids were starved for $\sim 16 \mathrm{hrs}$ and then allowed to feed without disturbance for $15 \mathrm{~m}, 30 \mathrm{~m}, 1 \mathrm{hr}$, or 6hrs on CYDV-RPV infected plant material placed in petri dishes in the dark. At the end of each time interval, aphids were interrupted in their feeding via repeated, gentle strokes from a fine paintbrush until they removed their mouthparts from the plant and were observed to walk away from the feeding site. Individual aphids were then immediately transferred onto 10-day old healthy wheat plants. Individual plant-aphid pairs were caged within $20.8 \mathrm{~cm}$ x $6.5 \mathrm{~cm}$ vented plastic tubes to prevent aphid escape. After transfer, aphids from all acquisition time intervals were given 5 days to feed on healthy wheat plants, after which aphids were manually exterminated. Young wheat plants were allowed to develop for a further 4 weeks to allow for virus infection and an increase in virus titer in leaf tissues. After this time, wheat plants were harvested and stored at $-80^{\circ} \mathrm{C}$ until infection status could be determined by extracting total RNA (RNeasy Plant Mini Kit, Qiagen Group, Germantown, MD), and using reversetranscription polymerase chain reaction (RT-PCR) to detect virus presence in individual plants. Each acquisition feeding interval, involving 10 aphids and 10 wheat plants, was 
replicated 4 times. Transmission efficiency was calculated as the proportion of wheat plants testing positive for CVDV-RPV from each acquisition interval.

To assess the impact of acquisition access period $(15 \mathrm{~m}, 30 \mathrm{~m}, 1 \mathrm{hr}$, or $6 \mathrm{hrs})$ on the

transmission efficiency $R$. padi aphids, the proportion of wheat plants testing positive for CYDV-RPV was compared across acquisition access periods using analysis of variance (Proc Mixed, SAS version 9.2, SAS Institute, Cary, NC). Data were arcsine square root transformed to meet the assumptions of ANOVA.

\section{RESULTS}

There was no significant impact of acquisition access period on the transmission efficiency of CYDV-RPV by $R$. padi aphids (Fig. $16, F_{3,12}=0.36, p=0.79$ ). There was no detectable trend of increasing or decreasing transmission efficiency as vector acquisition access period changed, and acquisition access periods did not differ significantly from each other in the proportion of plants testing positive for CYDV-RPV. In general, transmission efficiencies were in the 40\% - 65\% range across the four AAPs tested.

\section{DISCUSSION}

Vector feeding times, as well as the identity of specific host-vector-pathogen trios, are known to influence the efficiency with which pathogen transmission occurs (Power and Gray 1995). It is often the case for persistently-transmitted pathogens like the B/CYDVs that a longer feeding period increases the efficiency of pathogen transfer. However, in experimentally manipulating the time that $R$. padi aphids had to acquire the CYDV pathogen, I was unable to detect an impact of altering vector feeding time on the success of pathogen transfer in wheat plants (Fig. 16). While there were no significant 
trends, it was interesting to note that pathogen transmission by $R$. padi aphids was possible after acquisition access periods of as little as 15 minutes; a result similar to that observed by Gray et al (1991) in their virus acquisition experiments which involved the same vector, but a different host species.

There are several possible reasons for why I was unable to detect an impact of acquisition access period on pathogen transmission efficiency. First, I may not have included the key window of time required by $R$. padi aphids to effectively acquire the CYDV pathogen from infected wheat plants. The time intervals I chose may have been too short, as compared to the optimal 24-48hr feeding time (Power and Gray 1995), to allow me to see consistently greater transmission efficiencies in some treatments but not others. Conversely, the shortest AAP I used in my experiments $(15 \mathrm{~m})$ could have been too long to detect the minimum feeding time required by $R$. padi aphids to transmit CYDV-RPV. Second, it is possible that during the acquisition feeding period or even during the inoculation interval on the healthy wheat plants, that $R$. padi aphids did not settle and feed in a manner conducive to pathogen transfer. For example, if aphids moved from one site to another, probing plant tissue and feeding in short bouts, then the efficiency of pathogen transmission (acquisition and/or inoculation) could have been reduced. Furthermore, because I did not make visual observations of aphids during the acquisition access period in petri dishes, or after the initial transfer of aphids onto healthy wheat plants, it is possible that vectors did not truly settle to feed for the allotted time period which could have influenced pathogen transmission. However, I have used this method previously with great success. 
Although I was unable to find measurable effects of vector acquisition times on the efficiency of pathogen transmission, my results may yet contribute valuable insight into the complexities that are inherent to vector-borne pathogen systems. For example, I observed a high degree of variation in transmission efficiencies across replicates of individual AAP treatments, even though my experiments were conducted in an 'interaction vacuum' (i.e. no other organisms present besides the vector and the plant). This highlights how much the simple act of vector feeding can vary, even when vectors are in a controlled environment. Therefore, as we make predictions about how pathogen prevalence may be altered by the impacts of predators and competitors on vector populations, we must realize that the effects of these interactions will be layered on top of an already variable and dynamic process. 


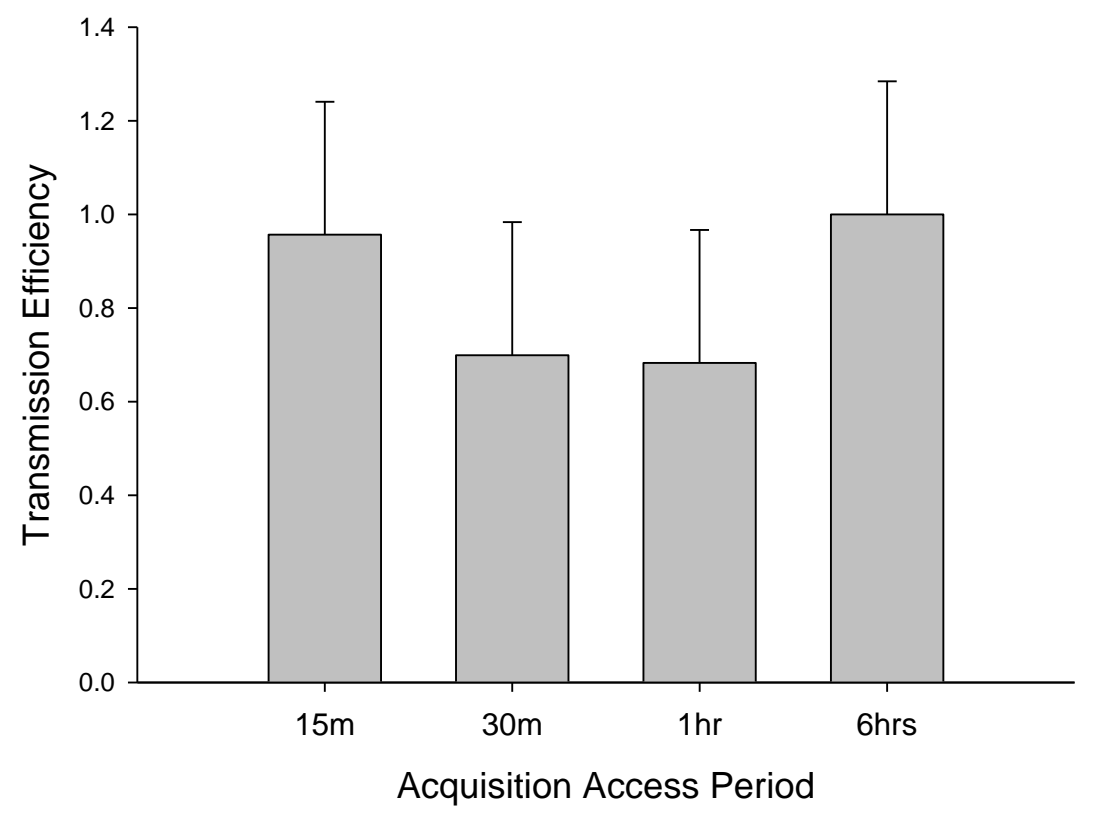

Figure 16. The impact of vector acquisition feeding time (acquisition access period) on the transmission efficiency (proportion of plants infected) of CYDVRPV by bird cherry-oat aphids (Rhopalosiphum padi) in soft red winter wheat. LSmeans \pm 1 SEM are shown. 


\section{LITERATURE CITED}

Agrios, G. 2005. Plant Pathology. 5th eds. New York: Academic Press.

Altieri, M. A. 1999. The ecological role of biodiversity in agroecosystems. Agriculture, Ecosystems \& Environment 74:19-31.

Balvanera, P., A. B. Pfisterer, N. Buchmann, J. S. He, T. Nakashizuka, D. Raffaelli, and B. Schmid. 2006. Quantifying the evidence for biodiversity effects on ecosystem functioning and services. Ecology Letters 9:1146-1156.

Banks, P., J. Davidson, H. Bariana, and P. Larkin. 1995. Effects of barley yellow dwarf virus on the yield of winter wheat. Australian Journal of Agricultural Research 46:935-946.

Belliure, B., R. Amorós-Jiménez, A. Fereres, and M. Marcos-García. 2011. Antipredator behaviour of Myzus persicae affects transmission efficiency of Broad bean wilt virus 1. Virus research 159:206-214.

Bianchi, F. J. J. A. and W. v. d. Werf. 2004. Model evaluation of the function of prey in non-crop habitats for biological control by ladybeetles in agricultural landscapes. Ecological Modelling 171:177-193.

Borer, E. T., C. E. Mitchell, A. G. Power, and E. W. Seabloom. 2009. Consumers indirectly increase infection risk in grassland food webs. Proceedings of the National Academy of Sciences 106:503-506.

Brewer, M. and N. Elliott. 2004. Biological Control of Cereal Aphids in North America and Mediating Effects of Host Plant and Habitat Manipulations*. Annual Reviews in Entomology 49:219-242.

Bruno, J. F. and B. J. Cardinale. 2008. Cascading Effects of Predator Richness. Frontiers in Ecology and the Environment 6:539-546.

Bruno, J. F. and M. I. O'Connor. 2005. Cascading effects of predator diversity and omnivory in a marine food web. Ecology Letters 8:1048-1056.

Burnett, P. and R. Plumb. 1998. Present status of controlling barley yellow dwarf virus. Plant Virus Disease Control. A. Hadidi, RK Khetarpal, and H. Koganezawa, eds. American Phytopathological Society, St. Paul, MN:448-458.

Burney, D. A. and T. F. Flannery. 2005. Fifty millennia of catastrophic extinctions after human contact. Trends in Ecology \& Evolution 20:395-401. 
Byrnes, J., J. J. Stachowicz, K. M. Hultgren, A. R. Hughes, S. V. Olyarnik, and C. S. Thornbert. 2005. Predator diversity strengthens trophic cascades in kelp forests by modifying herbivore behaviour. Ecology Letters 9:61-71.

Cardinale, B. J., J. E. Duffy, A. Gonzalez, D. U. Hooper, C. Perrings, P. Venail, A. Narwani, G. M. Mace, D. Tilman, and D. A. Wardle. 2012. Biodiversity loss and its impact on humanity. Nature 486:59-67.

Cardinale, B. J., C. T. Harvey, K. Gross, and A. R. Ives. 2003. Biodiversity and biocontrol: emergent impacts of a multiple-enemy assemblage on pest suppression and crop yield in an agroecosystem. Ecology Letters 6:857-865.

Cardinale, B. J., M. A. Palmer, and S. J. Collins. 2002. Species diversity enhances ecosystem functioning through interspecific facilitation. Nature 415:426-429.

Cardinale, B. J., D. Srivastava, J. E. Duffy, J. P. Wright, A. L. Downing, M. Sankaran, and C. Jouseau. 2006. Effects of biodiversity on the functioning of trophic groups and ecosystems. Nature 443:989-992.

Carlson, J. C., L. A. Dyer, F. X. Omlin, and J. C. Beier. 2009. Diversity cascades and malaria vectors. Journal of medical entomology 46:460.

Cottingham, K., B. Brown, and J. Lennon. 2001. Biodiversity may regulate the temporal variability of ecological systems. Ecology Letters 4:72-85.

Cronin, J. T., K. J. Haynes, and F. Dillemuth. 2004. Spider effects on planthopper mortality, dispersal, and spatial population dynamics. Ecology 85:2134-2143.

Crowder, D. W., T. D. Northfield, M. R. Strand, and W. E. Snyder. 2010. Organic agriculture promotes evenness and natural pest control. Nature 466:109-112.

D'Arcy, C. J. and P. A. Burnett. 1995. Barley yellow dwarf: 40 years of progress. American Phytopathological Society (APS Press).

Daszak, P., A. A. Cunningham, and A. D. Hyatt. 2000. Emerging infectious diseases of wildlife - Threats to biodiversity and human health. Science 287:443-449.

Denno, R. F., M. S. Mitter, G. A. Langellotto, C. Gratton, and D. L. Finke. 2004. Interactions between a hunting spider and a web-builder: consequences of intraguild predation and cannibalism for prey suppression. Ecological Entomology 29:566-578.

Diepenbrock, L. M. and D. L. Finke. 2012. Refuge for native lady beetles (Coccinellidae) in perennial grassland habitats. Insect Conservation and Diversity.

Dobson, A. 2004. Population dynamics of pathogens with multiple host species. The American Naturalist 164:S64-S78. 
Dobson, A., D. M. Lodge, J. Alder, G. S. Cumming, J. Keymer, J. McGlade, H. A. Mooney, J. A. Rusak, O. Sala, V. Wolters, D. H. Wall, R. Winfree, and M. A. Xenopoulos. 2006. Habitat loss, trophic collapse, and the decline of ecosystem services. Ecology 87:1915-1924.

Douglass, J. G., J. E. Duffy, and J. F. Bruno. 2008. Herbivore and predator diversity interactively affect ecosystem properties in an experimental marine community. Ecology Letters 11:598-608.

Duffy, J. E. 2003. Biodiversity loss, trophic skew and ecosystem functioning. Ecology Letters 6:680-687.

Duffy, M. A., J. M. Housley, R. M. Penczykowski, C. E. Caceres, and S. R. Hall. 2011. Unhealthy herds: indirect effects of predators enhance two drivers of disease spread. Functional Ecology 25:945-953.

Evans, E. 1991. Intra versus interspecific interactions of ladybeetles (Coleoptera: Coccinellidae) attacking aphids. Oecologia 87:401-408.

Ezenwa, V. O., M. S. Godsey, R. J. King, and S. C. Guptill. 2006. Avian diversity and West Nile virus: testing associations between biodiversity and infectious disease risk. Proceedings of the Royal Society B: Biological Sciences 273:109-117.

Finke, D. L. 2012. Contrasting the consumptive and non-consumptive cascading effects of natural enemies on vector-borne pathogens. Entomologia Experimentalis et Applicata 144:45-55.

Finke, D. L. and R. F. Denno. 2004. Predator diversity dampens trophic cascades. Nature 429:407-410.

Finke, D. L. and R. F. Denno. 2005. Predator diversity and the functioning of ecosystems: the role of intraguild predation in dampening trophic cascades. Ecology Letters 8:1299-1306.

Finke, D. L. and W. E. Snyder. 2008. Niche partitioning increases resource exploitation by diverse communities. Science 321:1488-1490.

Finke, D. L. and W. E. Snyder. 2010. Conserving the benefits of predator biodiversity. Biological Conservation 143:2260-2269.

France, K. E. and J. E. Duffy. 2006. Diversity and dispersal interactively affect predictability of ecosystem function. Nature 441:1139-1143.

Fukami, T., S. Naeem, and D. A. Wardle. 2001. On similarity among local communities in biodiversity experiments. Oikos 95:340-348. 
Garibaldi, L. A., I. Steffan-Dewenter, R. Winfree, M. A. Aizen, R. Bommarco, S. A. Cunningham, C. Kremen, L. G. Carvalheiro, L. D. Harder, and O. Afik. 2013. Wild Pollinators Enhance Fruit Set of Crops Regardless of Honey Bee Abundance. Science.

Gildow, F. E. 1987. Virus-Membrane Interactions Involved in Circulative Transmission of Luteoviruses by Aphids. Pages 93-120 Current topics in vector research. Springer.

Gray, S. and F. E. Gildow. 2003. Luteovirus-Aphid Interactions. Annual Review of Phytopathology 41:539-566.

Gray, S. M. and N. Banerjee. 1999. Mechanisms of arthropod transmission of plant and animal viruses. Microbiology and Molecular Biology Reviews 63:128-148.

Gray, S. M., A. G. Power, D. M. Smith, A. J. Seaman, and N. S. Altman. 1991. Aphid Transmission of Barley Yellow Dwarf Virus: Acquisition Access Periods and Virus Concentration Requirements. Phytopathology:539-545.

Griffin, C. A. and J. S. Thaler. 2006. Insect predators affect plant resistance via density-and trait-mediated indirect interactions. Ecology Letters 9:338-346.

Griffin, J. N. and B. R. Silliman. 2011. Predator diversity stabilizes and strengthens trophic control of a keystone grazer. Biology letters 7:79-82.

Haddad, N. M., G. M. Crutsinger, K. Gross, J. Haarstad, and D. Tilman. 2011. Plant diversity and the stability of foodwebs. Ecology Letters 14:42-46.

Hector, A., B. Schmid, C. Beierkuhnlein, M. C. Caldeira, M. Diemer, P. G. Dimitrakopoulos, J. A. Finn, H. Freitas, P. S. Giller, J. Good, R. Harris, P. Hogberg, K. Huss-Danell, J. Joshi, A. Jumpponen, C. Korner, P. W. Leadley, M. Loreau, A. Minns, C. P. H. Mulder, G. O'Donovan, S. J. Otway, J. S. Pereira, A. Prinz, D. J. Read, M. Scherer-Lorenzen, E. D. Schulze, A. S. D. Siamantziouras, E. M. Spehn, A. C. Terry, A. Y. Troumbis, F. I. Woodward, S. Yachi, and J. H. Lawton. 1999. Plant diversity and productivity experiments in European grasslands. Science 286:1123-1127.

Hironori, Y. and S. Katsuhiro. 1997. Cannibalism and interspecific predation in two predatory ladybirds in relation to prey abundance in the field. Entomophaga 42:153-163.

Hodge, S., J. Hardie, and G. Powell. 2010. Parasitoids aid dispersal of a nonpersistently transmitted plant virus by disturbing the aphid vector. Agricultural and Forest Entomology 13:83-88. 
Hodge, S. and G. Powell. 2008. Complex interactions between a plant pathogen and insect parasitoid via the shared vector-host: consequences for host plant infection. Oecologia 157:387-397.

Holt, Robert D. and M. Roy. 2007. Predation Can Increase the Prevalence of Infectious Disease. The American Naturalist 169:690-699.

Hooper, D., F. Chapin Iii, J. Ewel, A. Hector, P. Inchausti, S. Lavorel, J. Lawton, D. Lodge, M. Loreau, and S. Naeem. 2005. Effects of biodiversity on ecosystem functioning: a consensus of current knowledge. Ecological monographs 75:3-35.

Hooper, D. U. and J. S. Dukes. 2004. Overyielding among plant functional groups in a long-term experiment. Ecology Letters 7:95-105.

Howeth, J. G. and M. A. Leibold. 2010. Species dispersal rates alter diversity and ecosystem stability in pond metacommunities. Ecology 91:2727-2741.

Huston, M. A. 1997. Hidden treatments in ecological experiments: re-evaluating the ecosystem function of biodiversity. Oecologia 110:449-460.

Irwin, M. E. and J. M. Thresh. 1990. Epidemiology of Barley Yellow Dwarf: A Study in Ecological Complexity. Annual Review of Phytopathology:393-424.

Ives, A. R., B. J. Cardinale, and W. E. Snyder. 2005. A synthesis of subdisciplines: predator-prey interactions, and biodiversity and ecosystem functioning. Ecology Letters 8:102-116.

Jabbour, R., D. W. Crowder, E. A. Aultman, and W. E. Snyder. 2011. Entomopathogen biodiversity increases host mortality. Biological Control 59:277-283.

Jiang, L. and Z. Pu. 2009. Different Effects of Species Diversity on Temporal Stability in Single-Trophic and Multitrophic Communities. The American Naturalist 174:651659.

Johnson, P. and D. Thieltges. 2010. Diversity, decoys and the dilution effect: how ecological communities affect disease risk. The Journal of Experimental Biology 213:961-970.

Johnson, P. T. J., R. B. Hartson, D. J. Larson, and D. R. Sutherland. 2008. Diversity and disease: community structure drives parasite transmission and host fitness. Ecology Letters 11:1017-1026.

Jonsson, M., F. Johansson, C. Karlsson, and T. Brodin. 2007. Intermediate predator impact on consumers weakens with increasing predator diversity in the presence of a top-predator. Acta Oecologica 31:79-85. 
Joseph, M. A. 2011. Major Cereal Grains Production and Use around the World. Pages 113 Advances in Cereal Science: Implications to Food Processing and Health Promotion. American Chemical Society.

Keesing, F., L. K. Belden, P. Daszak, A. Dobson, C. D. Harvell, R. D. Holt, P. Hudson, A. Jolles, K. E. Jones, C. E. Mitchell, S. S. Myers, T. Bogich, and R. S. Ostfeld. 2010. Impacts of biodiversity on the emergence and transmission of infectious diseases. Nature 468:647-652.

Keesing, F., R. D. Holt, and R. S. Ostfeld. 2006. Effects of species diversity on disease risk. Ecology Letters 9:485-498.

Kennedy, T. A., S. Naeem, K. M. Howe, J. M. H. Knops, D. Tilman, and P. Reich. 2002. Biodiversity as a barrier to ecological invasion. Nature 417:636-638.

Kilpatrick, A. M., P. Daszak, M. J. Jones, P. P. Marra, and L. D. Kramer. 2006. Host heterogeneity dominates West Nile virus transmission. Proceedings of the Royal Society B: Biological Sciences 273:2327-2333.

Knops, J. M., D. Tilman, d. N. Haddad, S. Naeem, C. Mitchell, J. Haarstad, M. Ritchie, K. Howe, P. Reich, and E. Siemann. 1999. Effects of plant species richness on invasion dynamics, disease outbreaks, insect abundances and diversity. Ecology Letters 2:286-293.

Kotler, B. P., L. Blaustein, and J. S. Brown. 1992. Predator facilitation: the combined effect of snakes and owls on the foraging behavior of gerbils. Pages 199-206 in Annales Zoologici Fennici.

Krauss, J., I. Gallenberger, and I. Steffan-Dewenter. 2011. Decreased Functional Diversity and Biological Pest Control in Conventional Compared to Organic Crop Fields. PLoS ONE 6:e19502.

Kring, T. J., F. E. Gilstrap, and G. J. Michels. 1985. Role of Indigenous Coccinellids in Regulating Greenbugs (Homoptera: Aphididae) on Texas Grain Sorghum. Journal of Economic Entomology 78:269-273.

Lafferty, K. D. 2004. Fishing for lobsters indirectly increases epidemics in sea urchins. Ecological Applications 14:1566-1573.

Landis, D. and W. Van der Werf. 1997. Early-season predation impacts the establishment of aphids and spread of beet yellows virus in sugar beet. Entomophaga 42:499516.

Letourneau, D. K., J. A. Jedlicka, S. G. Bothwell, and C. R. Moreno. 2009. Effects of natural enemy biodiversity on the suppression of arthropod herbivores in terrestrial ecosystems. Annual Review of Ecology, Evolution, and Systematics 40:573-592. 
LoGiudice, K., R. S. Ostfeld, K. A. Schmidt, and F. Keesing. 2003. The ecology of infectious disease: effects of host diversity and community composition on Lyme disease risk. Proceedings of the National Academy of Sciences 100:567-571.

Loreau, M. and A. Hector. 2001. Partitioning selection and complementarity in biodiversity experiments. Nature 412:72-76.

Loreau, M., N. Mouquet, and A. Gonzalez. 2003. Biodiversity as spatial insurance in heterogeneous landscapes. Proceedings of the National Academy of Sciences 100:12765-12770.

Loreau, M., S. Naeem, P. Inchausti, J. Bengtsson, J. P. Grime, A. Hector, D. U. Hooper, M. A. Huston, D. Raffaelli, B. Schmid, D. Tilman, and D. A. Wardle. 2001. Biodiversity and ecosystem functioning: current knowledge and future challenges. Science 294:804-808.

Losey, J. E. and R. F. Denno. 1998a. The escape response of pea aphids to foliar-foraging predators: factors affecting dropping behaviour. Ecological Entomology 23:53-61.

Losey, J. E. and R. F. Denno. 1998b. Positive predator-predator interactions: enhanced predation rates and synergistic suppression of aphid populations. Ecology 79:2143-2152.

Losey, J. E. and Vaughan. 2006. The economic value of ecological services provided by insects. BioScience 56:311-323.

McCann, K., A. Hastings, and G. R. Huxel. 1998. Weak trophic interactions and the balance of nature. Nature 395:794-798.

McGrady-Steed, J., P. M. Harris, and P. J. Morin. 1997. Biodiversity regulates ecosystem predictability. Nature 390:162-165.

Miller and, W. A. and L. Rasochová. 1997. Barley yellow dwarf viruses. Annual Review of Phytopathology 35:167-190.

Moore, S. M., E. T. Borer, and P. R. Hosseini. 2009. Predators indirectly control vectorborne disease: linking predator-prey and host-pathogen models. Journal of The Royal Society Interface 7:161-176.

Naeem, S. and S. Li. 1997. Biodiversity enhances ecosystem reliability. Nature 390:507509.

Nault, L. 1997. Arthropod transmission of plant viruses: a new synthesis. Annals of the Entomological Society of America 90:521-541.

Nelson, E. H. 2007. Predator avoidance behavior in the pea aphid: costs, frequency, and population consequences. Oecologia 151:22-32. 
Obrycki, J. J., K. L. Giles, and A. M. Ormord. 1998. Interactions between an introduced and indigenous coccinellid species at different prey densities. Oecologia 117:279285.

Obrycki, J. J., J. D. Harwood, T. J. Kring, and R. J. O'Neil. 2009. Aphidophagy by Coccinellidae: Application of biological control in agroecosystems. Biological Control 51:244-254.

Obrycki, J. J. and T. J. Kring. 1998. Predaceous Coccinellidae in biological control. Annual Review of Entomology 43:295-321.

Ostfeld, R. S. and R. D. Holt. 2004. Are predators good for your health? Evaluating evidence for top-down regulation of zoonotic disease resevoirs. Frontiers in Ecology and the Environment 2:13-20.

Otto, S. B., E. L. Berlow, N. E. Rank, J. Smiley, and U. Brose. 2008. Predator diversity and identity drive interaction strength and trophic cascades in a food web. Ecology 89:134-144.

Pauly, D., V. Christensen, J. Dalsgaard, R. Froese, and F. Torres. 1998. Fishing Down Marine Food Webs. Science 279:860-863.

Perry, K. L., F. L. Kolb, B. Sammons, C. Lawson, G. Cisar, and H. Ohm. 2000. Yield effects of Barley yellow dwarf virus in soft red winter wheat. Phytopathology 90:1043-1048.

Petchey, O. L. 2003. Integrating methods that investigate how complementarity influences ecosystem functioning. Oikos 101:323-330.

Petchey, O. L., P. T. McPhearson, T. M. Casey, and P. J. Morin. 1999. Environmental warming alters food-web structure and ecosystem function. Nature 402:69-72.

Pike, K. 1990. A review of barley yellow dwarf virus grain yield losses.in World Perspectives on Barley Yellow Dwarf International Workshop, Udine (Italy), 6-11 Jul 1987. CIMMYT.

Plumb, R. and J. Thresh. 1983. Barley yellow dwarf virus-a global problem. Plant virus epidemiology. The spread and control of insect-borne viruses:185-198.

Power, A. and S. Gray. 1995. Aphid transmission of barley yellow dwarf viruses: interactions between viruses, vectors, and host plants. Barley yellow dwarf 40:259-291.

Power, A. G. 1991. Virus spread and vector dynamics in genetically diverse plant populations. Ecology 72:232-241. 
Power, A. G. and C. E. Mitchell. 2004. Pathogen spillover in disease epidemics. The American Naturalist 164:S79-S89.

Power, A. G., A. J. Seaman, and S. M. Gray. 1991. Aphid transmission of barley yellow dwarf virus: Inoculation access periods and epidemiological implications. Phytopathology 81:545-548.

Prasad, R. P. and W. E. Snyder. 2006. Diverse trait-mediated interactions in a multipredator, multi-prey community. Ecology 87:1131-1137.

Preisser, E. L., D. I. Bolnick, and M. F. Benard. 2005. Scared to death? The effects of intimidation and consumption in predator-prey interactions. Ecology 86:501-509.

Ramirez, R. A. and W. E. Snyder. 2009. Scared sick? Predator-pathogen facilitation enhances exploitation of a shared resource. Ecology 90:2832-2839.

Reiss, J., J. R. Bridle, J. M. Montoya, and G. Woodward. 2009. Emerging horizons in biodiversity and ecosystem functioning research. Trends in Ecology \& Evolution 24:505-514.

Reynolds, P. L. and J. F. Bruno. 2013. Multiple predator species alter prey behavior, population growth, and a trophic cascade in a model estuarine food web. Ecological monographs 83:119-132.

Rice, M. and G. Wilde. 1988. Experimental evaluation of predators and parasitoids in suppressing greenbugs (Homoptera: Aphididae) in sorghum and wheat. Environmental entomology 17:836-841.

Roche, B., A. P. Dobson, J.-F. Guégan, and P. Rohani. 2012. Linking community and disease ecology: the impact of biodiversity on pathogen transmission. Philosophical Transactions of the Royal Society B: Biological Sciences 367:28072813.

Rochow, W. F. 1970. Barley Yellow Dwarf Virus: Phenotypic Mixing and Vector Specificity. Science 167:875-878.

Rooney, N., K. McCann, G. Gellner, and J. C. Moore. 2006. Structural asymmetry and the stability of diverse food webs. Nature 442:265-269.

Salkeld, D. J., K. A. Padgett, and J. H. Jones. 2013. A meta-analysis suggesting that the relationship between biodiversity and risk of zoonotic pathogen transmission is idiosyncratic. Ecology Letters:n/a-n/a.

Schmidt, M. H., A. Lauer, T. Purtauf, C. Thies, M. Schaefer, and T. Tscharntke. 2003. Relative importance of predators and parasitoids for cereal aphid control. Proceedings of the Royal Society of London. Series B: Biological Sciences 270:1905-1909. 
Schmidt, M. H., U. Thewes, C. Thies, and T. Tscharntke. 2004. Aphid suppression by natural enemies in mulched cereals. Entomologia Experimentalis et Applicata 113:87-93.

Schmitz, O., P. A. Hamback, and A. P. Beckerman. 2000. Trophic cascades in terrestrial systems: A review of the effects of carnivore removals on plants. The American Naturalist 155:141-153.

Schmitz, O. J. 1998. Direct and indirect effects of predation and predation risk in oldfield interaction webs. The American Naturalist 151:327-342.

Schmitz, O. J. 2007. Predator diversity and trophic interactions. Ecology 88:2415-2426.

Schmitz, O. J., V. Krivan, and O. Ovadia. 2004. Trophic cascades: the primacy of traitmediated indirect interactions. Ecology Letters 7:153-163.

Schmitz, O. J. and K. B. Suttle. 2001. Effects of top predator species on direct and indirect interactions in a food web. Ecology 82:2072-2081.

Smyrnioudis, I., R. Harrington, S. Clark, and N. Katis. 2001. The effect of natural enemies on the spread of barley yellow dwarf virus (BYDV) by Rhopalosiphum padi (Hemiptera: Aphididae). Bulletin of entomological research 91:301-306.

Snyder, W. E. 2009. Coccinellids in diverse communities: Which niche fits? Biological Control 51:323-335.

Snyder, W. E., S. N. Ballard, S. Yang, G. M. Clevenger, T. D. Miller, J. J. Ahn, T. D. Hatten, and A. A. Berryman. 2004. Complementary biocontrol of aphids by the ladybird beetle Harmonia axyridis and the parasitoid Aphelinus asychis on greenhouse roses. Biological Control 30:229-235.

Snyder, W. E., G. C. Chang, and R. P. Prasad. 2005. Conservation biological control: biodiversity influences the effectiveness of predators.in P. Barbosa and I. Castellanos, editors. Ecology of predator-prey interactions. Oxford University Press, London.

Snyder, W. E., G. B. Snyder, D. L. Finke, and C. S. Straub. 2006. Predator biodiversity strengthens herbivore suppression. Ecology Letters 9:789-796.

Soluk, D. A. and N. C. Collins. 1988. Synergistic interactions between fish and stoneflies: facilitation and interference among stream predators. Oikos 52:94-100.

Srivastava, D. S. and M. Vellend. 2005. Biodiversity-Ecosystem Function Research: Is It Relevant to Conservation? Annual Review of Ecology, Evolution, and Systematics 36:267-294. 
Stachowicz, J. J., H. Fried, R. W. Osman, and R. B. Whitlatch. 2002. Biodiversity, invasion resistance, and marine ecosystem function: reconciling pattern and process. Ecology 83:2575-2590.

Steffan, S. A. and W. E. Snyder. 2010. Cascading diversity effects transmitted exclusively by behavioral interactions. Ecology 91:2242-2252.

Straub, C. S., D. L. Finke, and W. E. Snyder. 2008. Are the conservation of natural enemy biodiversity and biological control compatible goals? Biological Control 45:225-237.

Straub, C. S. and W. E. Snyder. 2006. Species identity dominates the relationship between predator biodiversity and herbivore suppression. Ecology 87:277-282.

Straub, C. S. and W. E. Snyder. 2008. Increasing enemy biodiversity strengthens herbivore suppression on two plant species. Ecology 89:1605-1615.

Tamaki, G., J. E. Halfhill, and D. Hathaway. 1970. Dispersal and Reduction of Colonies of Pea Aphids1 by Aphidius smithi (Hymenoptera: Aphidiidae). Annals of the Entomological Society of America 63:973-980.

Thébault, E. and M. Loreau. 2005. Trophic interactions and the relationship between species diversity and ecosystem stability. The American Naturalist 166:E95-E114.

Thies, C., S. Haenke, C. Scherber, J. Bengtsson, R. Bommarco, L. W. Clement, P. Ceryngier, C. Dennis, M. Emmerson, V. Gagic, V. Hawro, J. Liira, W. W. Weisser, C. Winqvist, and T. Tscharntke. 2011. The relationship between agricultural intensification and biological control: experimental tests across Europe. Ecological Applications 21:2187-2196.

Tilman, D. 1997. Distinguishing between the effects of species diversity and species composition. Oikos 80.

Tilman, D., J. Fargione, B. Wolff, C. D'Antonio, A. Dobson, R. Howarth, D. Schindler, W. H. Schlesinger, D. Simberloff, and D. Swackhamer. 2001. Forecasting agriculturally driven global environmental change. Science 292:281-292.

Tilman, D., R. M. May, C. L. Lehman, and M. A. Nowak. 1994. Habitat destruction and the extinction debt. Nature 371:65-66.

Tilman, D., P. B. Reich, and J. M. H. Knops. 2006. Biodiversity and ecosystem stability in a decade-long grassland experiment. Nature 441:629-632.

Tscharntke, T., R. Bommarco, Y. Clough, T. O. Crist, D. Kleijn, T. A. Rand, J. M. Tylianakis, S. v. Nouhuys, and S. Vidal. 2007. Conservation biological control and enemy diversity on a landscape scale. Biological Control 43:294-309. 
Tylianakis, J. M. and C. M. Romo. 2010. Natural enemy diversity and biological control: making sense of the context-dependency. Basic and Applied Ecology 11:657-668.

Van Der Heijden, M. G. A., R. D. Bardgett, and N. M. Van Straalen. 2008. The unseen majority: soil microbes as drivers of plant diversity and productivity in terrestrial ecosystems. Ecology Letters 11:296-310.

Vitousek, P. M., H. A. Mooney, J. Lubchenco, and J. M. Melillo. 1997. Human domination of Earth's ecosystems. Science 277:494-499.

Wardle, D. A. 1999. Is "sampling effect" a problem for experiments investigating biodiversity-ecosystem function relationships? Oikos 87:403-407.

Weber, C. A., L. D. Godfrey, and P. A. Mauk. 1996. Effects of Parasitism by Lysiphlebus testaceipes (Hymenoptera: Aphidiidae) on Transmission of Beet Yellows Closterovirus by Bean Aphid (Homoptera: Aphididae). Journal of Economic Entomology 89:1431-1437.

Weigelt, A., J. Schumacher, C. Roscher, and B. Schmid. 2008. Does biodiversity increase spatial stability in plant community biomass? Ecology Letters 11:338-347.

Wilby, A., S. C. Villareal, L. P. Lan, K. L. Heong, and M. B. Thomas. 2005. Functional benefits of predator species diversity depend on prey identity. Ecological Entomology 30:497-501.

Wood, C. L. and K. D. Lafferty. 2012. Biodiversity and disease: a synthesis of ecological perspectives on Lyme disease transmission. Trends in Ecology \& Evolution.

Worm, B., E. B. Barbier, N. Beaumont, J. E. Duffy, C. Folke, B. S. Halpern, J. B. C. Jackson, H. K. Lotze, F. Micheli, S. R. Palumbi, E. Sala, K. A. Selkoe, J. J. Stachowicz, and R. Watson. 2006. Impacts of biodiversity loss on ocean ecosystem services. Science 314:787-790. 


\section{VITA}

Elizabeth Yim Long was born to William and Yim Chung Son Long on July 31, 1985 in Seoul, South Korea. Being part of a military family, she moved several times during her childhood and lived in a variety of places including South Korea, Central America, and the United States. However, her true 'home base' was located in Marion, North Carolina; a small town at the foothills of the Blue Ridge Mountains. It was here that she spent the majority of her growing years with her family. Elizabeth graduated from McDowell High School in May 2003, and went on to attend North Carolina State University in August of 2003. In May 2007, Elizabeth graduated Cum Laude from North Carolina State University with a Bachelor of Science degree in Biological Sciences. Upon graduating, Elizabeth joined a team of researchers on the Corridor Project, a large scale habitat fragmentation experiment aimed at understanding the consequences of human-mediated changes to the landscape for various ecosystem processes like seed dispersal and habitat restoration. In the spring of 2008, Elizabeth was accepted into the Plant, Insect, and Microbial Sciences doctoral program at the University of Missouri, where she was awarded a four-year Life Sciences Fellowship to conduct research exploring the role of predator diversity in vector-borne disease dynamics with Dr. Deborah Finke. She graduated with her PhD in May 2013. Over the course of her studies and research, Elizabeth has worked in a variety of settings spanning the fields of plant, animal and insect ecology, as well as veterinary health care, and children's tennis instruction/training. 